Ministry of Education Iraqi Directorate of Education Baghdad Karkh III

First Conference Department of Preparation and Training Division of Research and Studies

وزارة التربية العراقية مديرية تريية بغداد الكرخ الثالثة الهؤتمر الاول قسم الاعداد والتلدريب شعبة البحوث واللداسات

\title{
Work stress and its relation to educational leadership among school principals
}

\author{
Shahad Sabeh Hammed \\ Directorate of Baghdad Education Karkh III, Ministry of Education, Baghdad, Iraq
}

\begin{abstract}
Research Abstract: -. In order to achieve the research objectives, the researcher applied the scale to a sample adult (50) of principals of primary and secondary schools who were randomized. After processing the data statistically, the research reached the following results:1There is an inverse correlation between work pressures and educational leadership. there are same recommendations and suggestions such as 1- Interested in modernizing school management systems in school, leading to the development of its abilities in dealing with the pressures of work. The research proposals are 1- Relationship of psychological stress to school principals with personal variables that relate to age and experience.
\end{abstract}

Keywords: Imaginative introductory, imaginative figure, Sonallah Ibrahim.

\section{ضغوط العمل وعلاقته بالقيادة التريوية للى مليري المدارس}

\author{
ثهد صبيع حميل \\ وزارة التربية، مديرية تربية بغداد الكرخ الثالثة، بغداد، العراق
}

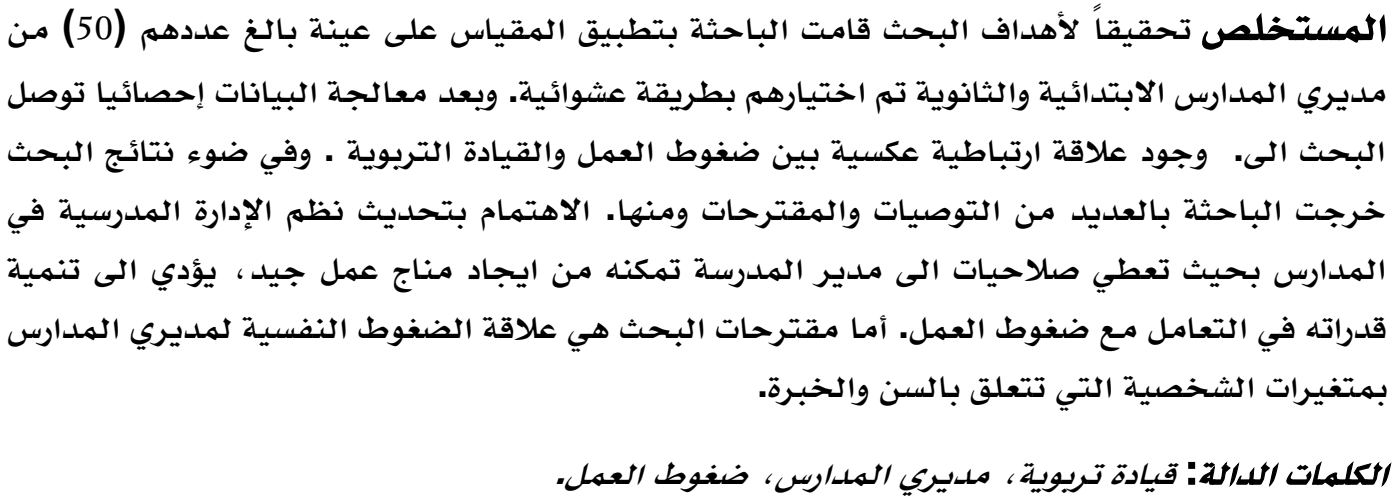

Hammed, S. (2019). Work stress and its relation to educational leadership among school principals. Journal Pon Science Research, 2(3), 331-355. 
نظرا للتغيرات التربوية والتفجير المعرفي الهائل الذي يميز العصر الراهن , فقد تم التأكيد على أهمية

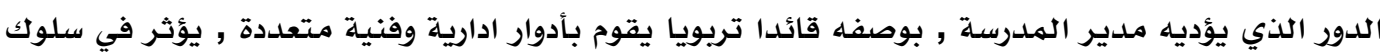

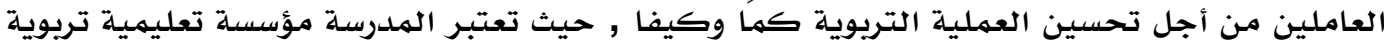

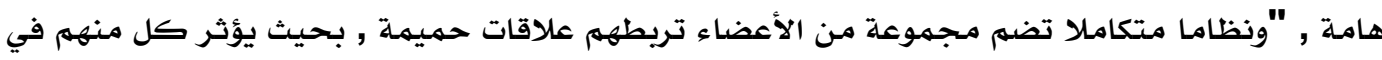
الأخر ويتأثر بهم , لذذكأك فأن تعرض أي فرد في المؤسسة لظروف غير مناسبة , أو لأي اضطراب سوف

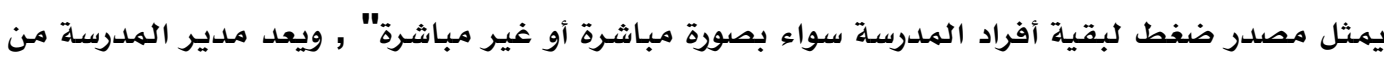

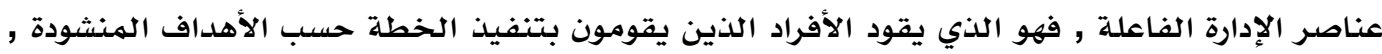

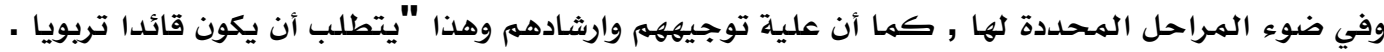

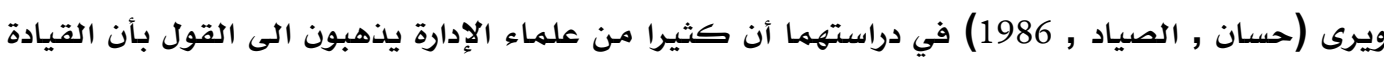

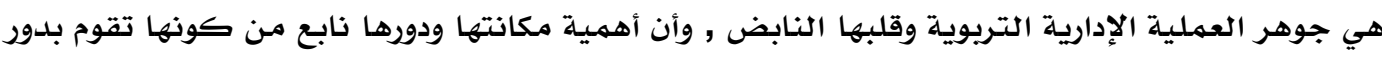

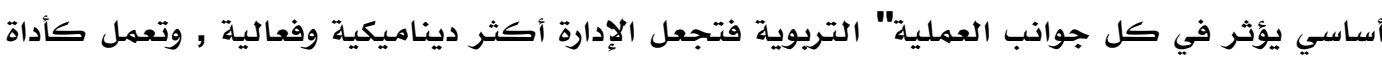

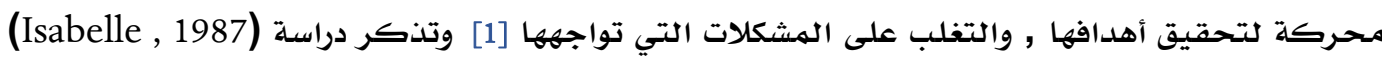

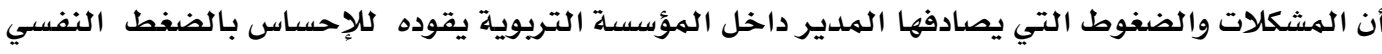

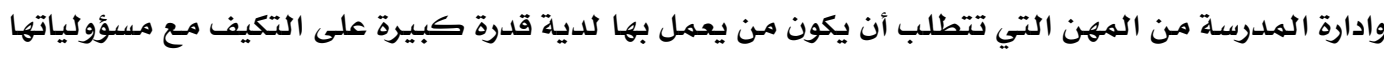

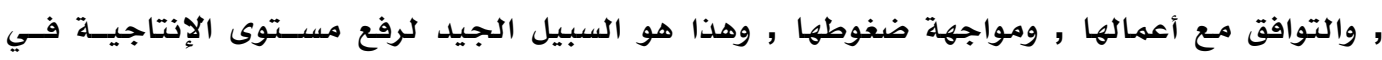

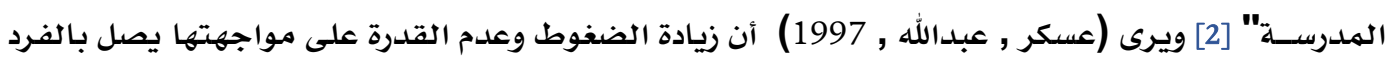

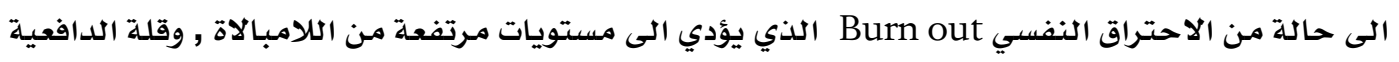

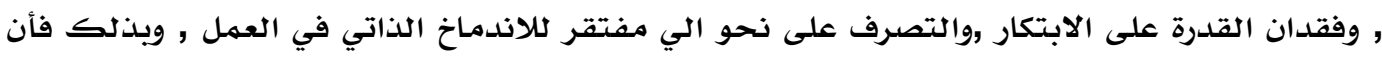

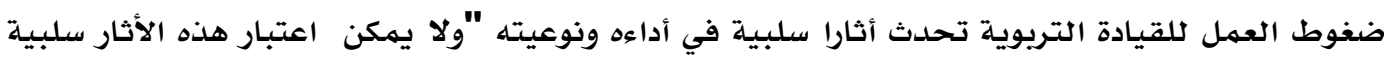

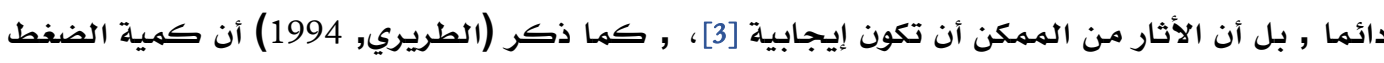

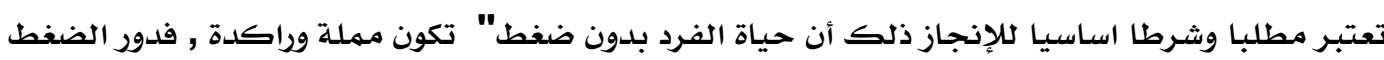

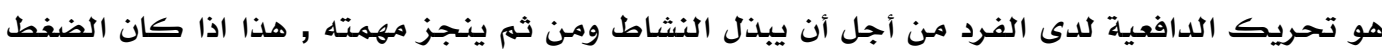

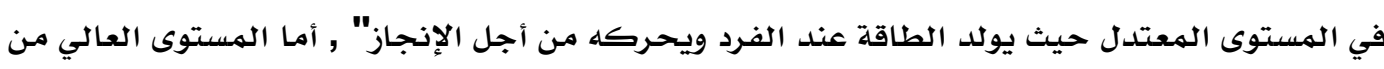

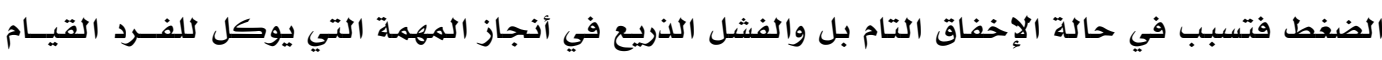

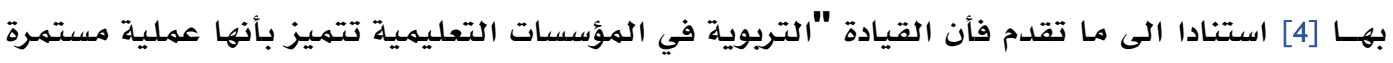

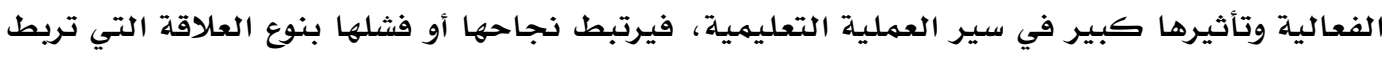

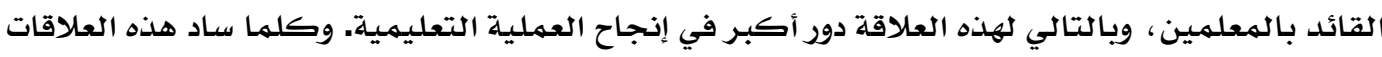

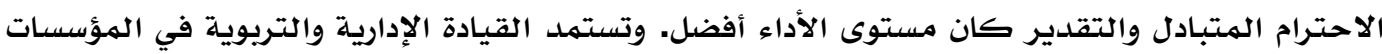

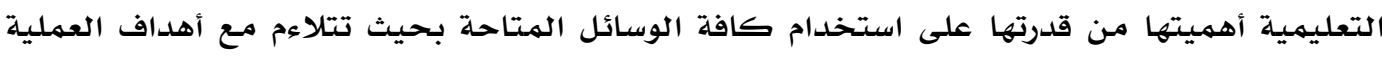

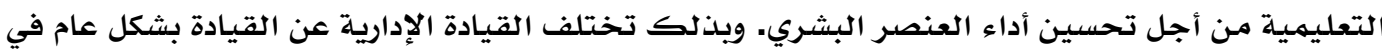

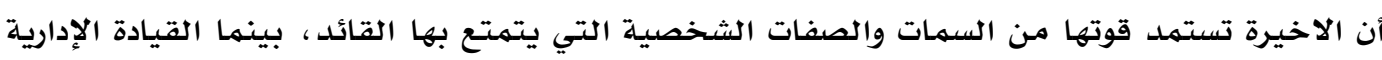

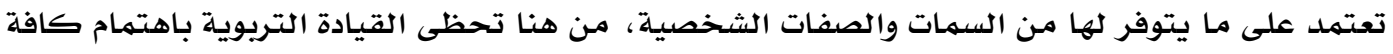

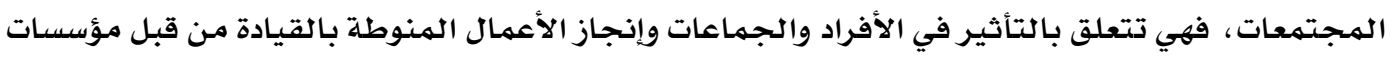

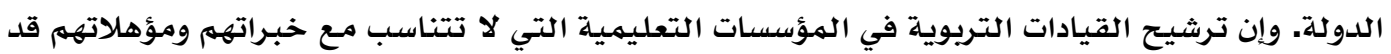

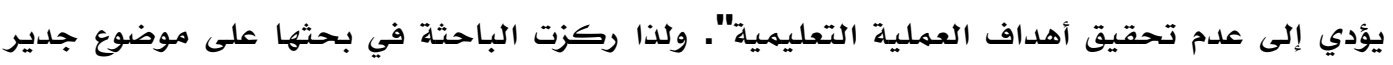


بالاهتمام وهو ضغوط العمل وعلاقته بالقيادة التربوية لدى مديري المدارس، وانطلاقا مما تقدم فأن

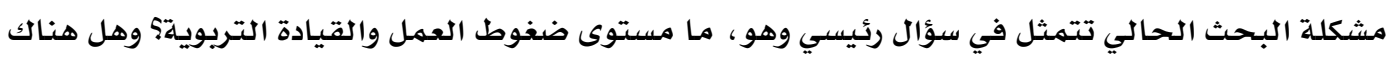

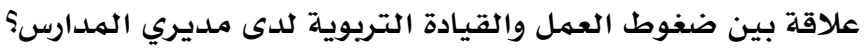

\section{•}

تعد المؤسسات التربوية وحدات اجتماعية تتألف من أفراد يعملون معا من اجل الوصول أو تحقيق أهداف

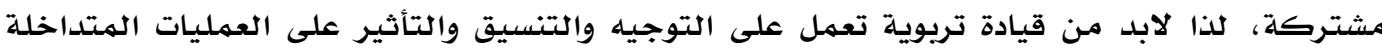

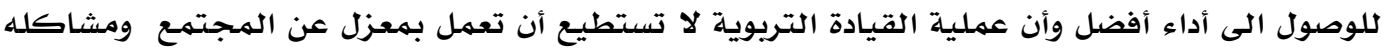

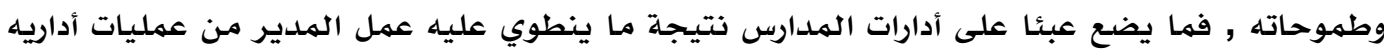

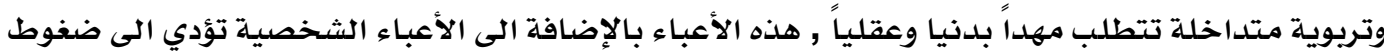

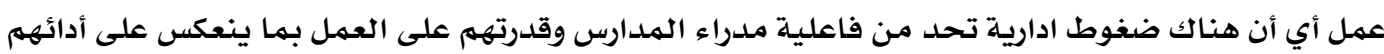

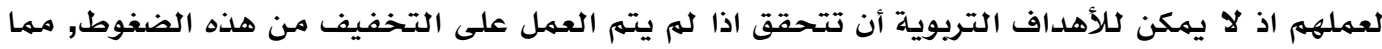

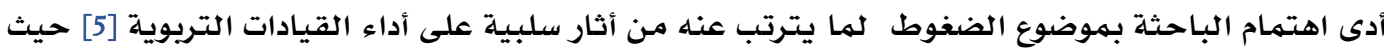

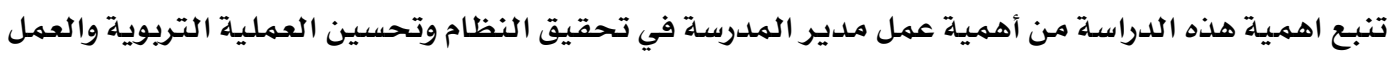

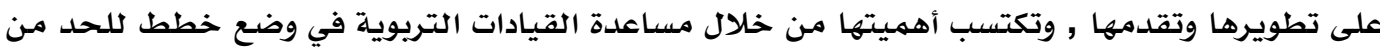

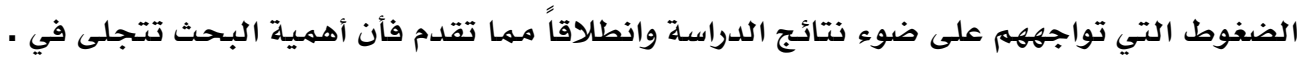
1) تقديم خلفية نظرية في مجال التربية بحيث تعتبر هذه الدراسة إحدى الدراسـات القليلة التي

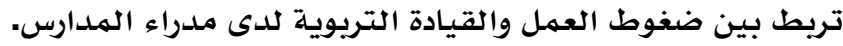

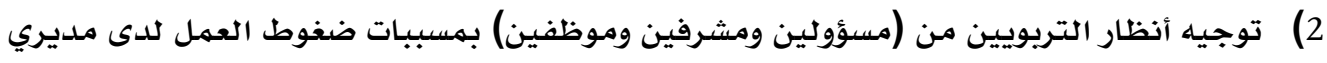

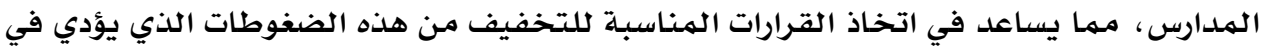
النهاية الى قيادة تربوية ناجحة وجيدة والتي تعتبر البوتقة التي تنصهر داخلها كافة التهات المفاهيه والاستراتيجيات والسياسات فيؤثر ذلك تأثيرا مباشرا على المعلمين والطلبة الذينية النين هم أهمر مخرجات العملية التربوية. 3) تمثل الدراسة الحالية محاولة هادفة للمساهمة في تنمية ورعاية المعلمين باعتبارهم أهم مورد

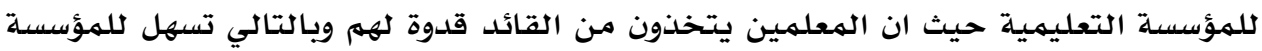

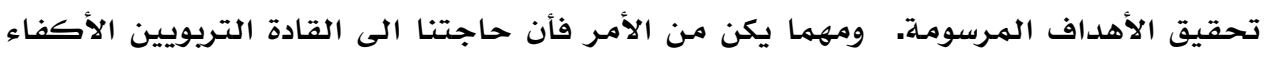

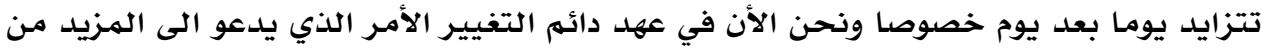

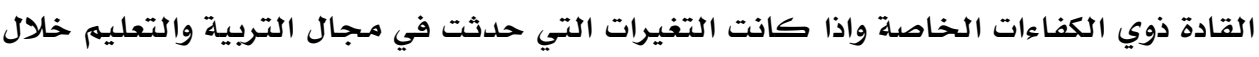

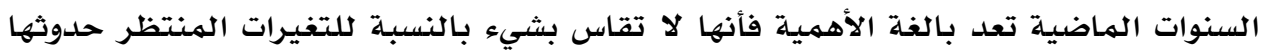

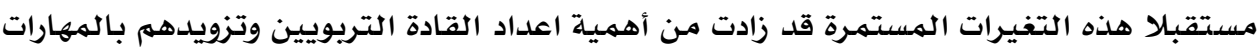

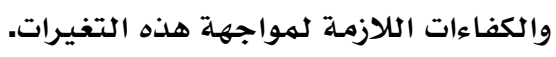

تعرف مستوى ضغوط العمل لدى مديري المدارس، تعرف مستوى القيادة التريويـة لدى مديري المدارس، تعرف طبيعة العلاقة بين ضغوط العمل والقيادة التربوية لدى مديري المدارس.

Hammed, S. (2019). Work stress and its relation to educational leadership among school principals. Journal Pon Science Research, 2(3), 331-355. 
تحدد البحث الحالي بعدد من مدراء المدارس التابعة الى مديرية تربية بغداد الكرج /3 ولككلا الجنسين (ذكور - أناث) من المدارس الابتدائية والثانوية وللعام الدراسي 2017-2018.

تحليل المصطلهات

أولا ضغوط العمل Work stress عرفت ضغوط العمل بتعريفات عدة منها:

نور حمدان ومثمان 2011 هو "الاستجابة لزمرة انفعالات سلبية كالغضب والقلق والاكتئاب والتي

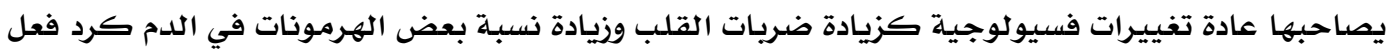
للضغوط التي يتعرض لها الشخص كنتيجة لمتطلبات المهنة وقد يشكل ذلك تهديدا لذاته او يجعله يشعر بالسعادة فينخفض التهرض لها الشخيد المدرك" [6]ـ جيملخه (Gmelch) 1998 هو تأثير داخلي يخلق حالة من عدم التوازن النفسي أو الجسمي داخل الفرد،

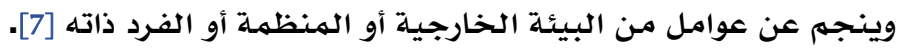

إبراهيم 1994 بأنها الحالة الناتجة عن عدم التوازن بين مطالب الموقف وقدرة استجابة الفرد لهــا الموقف [8].

اما التعريف الإجرائي لضغوط العمل فيتمثل بمجموع الدرجات التي يحصل عليها المستجيب في مقياس ضغوط العمل ثانيا القيادة التربوية Leader ship عرفت بتعريفات عدة منها: شيمالس 2000 Chemers هي قدرة الفرد على التأثير في شخص أو جماعة، وتوجيهـه وإرثادهم لنيل

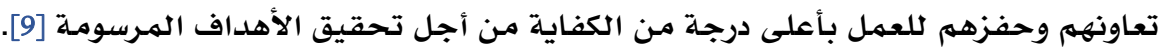
غولدنبرغ 1990 Goldenberg "هي القدرة على التأثير على سلوك أفراد الجماعة وتنسيق جهودهم

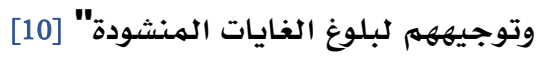

وايك 2994 Weick عملية التأثير وإلهاب الحماس في الأفراد للقيام بعملهم بحماس وطوعية دون الحاجة إلى استخدام السلطة الرسمية [11]. اما التعريف الإجرائي للقيادة التريوية فيتمثل بمجموع الدرجات التي يحصل عليها المستجيب في مقياس القيادة التربوية.

\section{• • • الإطار النظري ودراسات سابقة}

Theories Job Stress نظريات ضغوط العمل

أولاً نظرية هانس (Hans selu ، 1976) لقد ذكر سيلي هانس وهو من أشهر الباحثين في ضغوط العمل

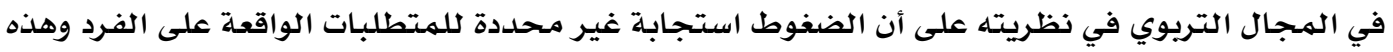

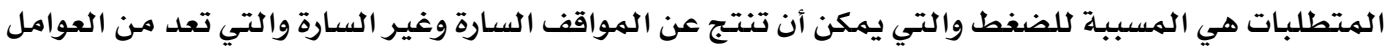

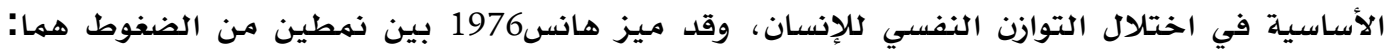

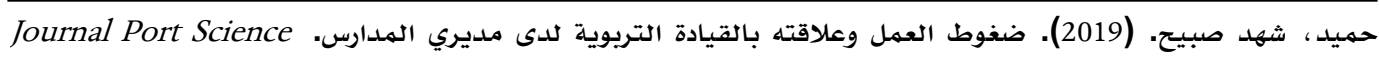


الضغوط السارة Eustress والضغوط المكدرة Distress ،ومن خلال أبحاثه لاحظ بعد حقن فئران تجاريه

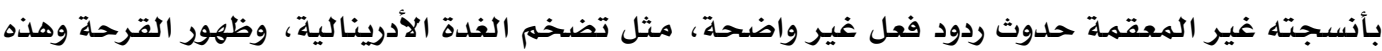

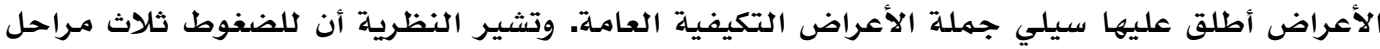

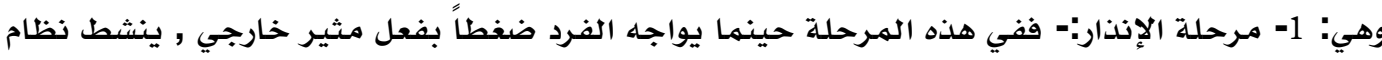

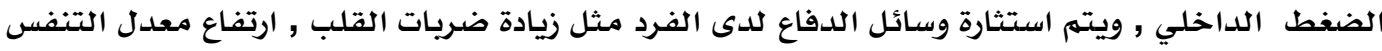

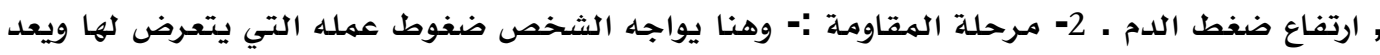

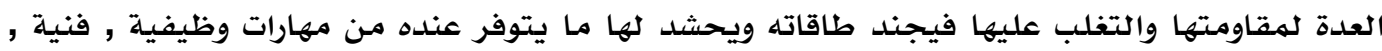

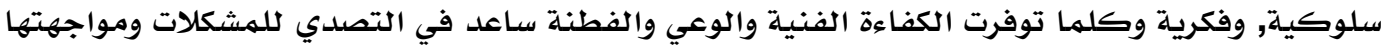
والتغلب على الضغوط والعكس صحيح كما ان المناج التنظيمي كلما كان جيد وليد وسائد في المؤسسات

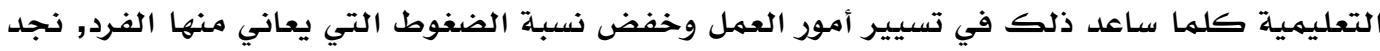

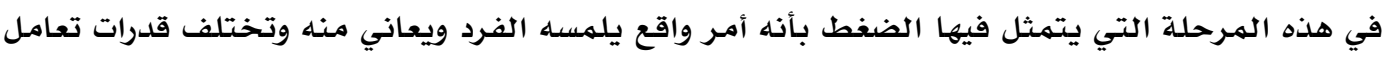

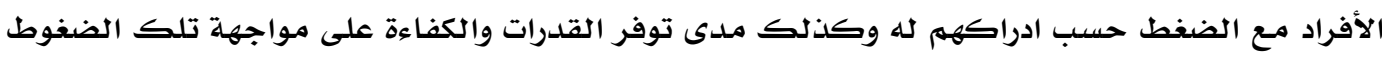

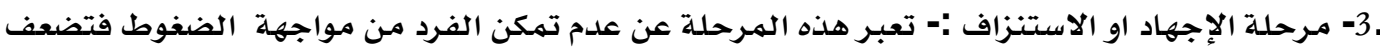

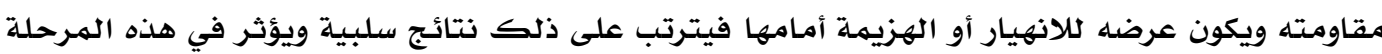
أيضا من حيث سرعتها ودرجة حدتها [12].

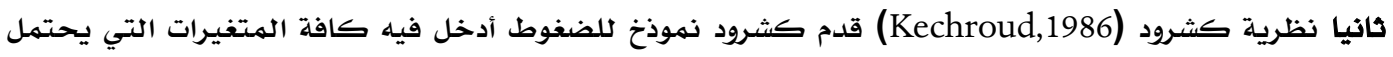

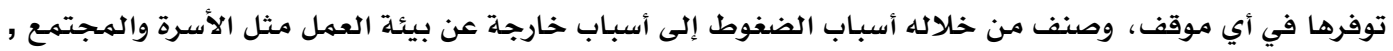

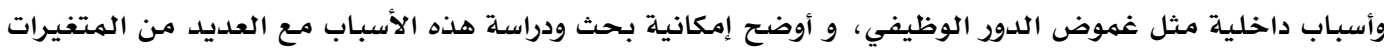

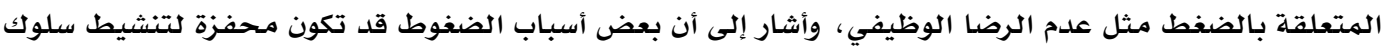

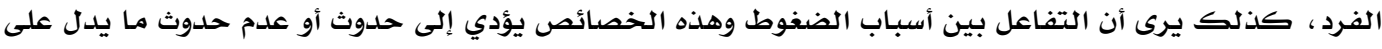

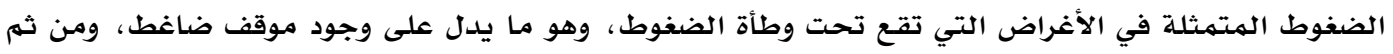

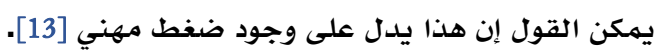

من خلال العرض للنظريات السابقة نرى أن كلا منها قد ركز الاهتمام على جانب من جوانب ضغوط العان العمل حيث العيث

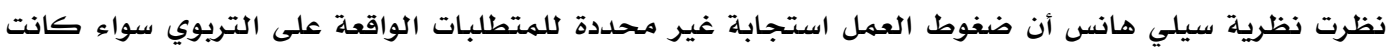

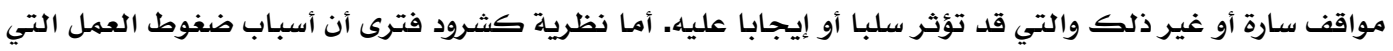

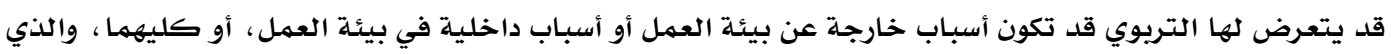

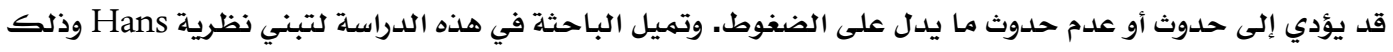

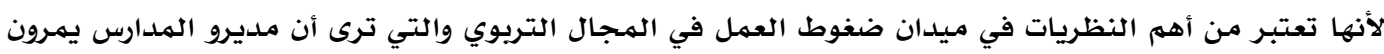

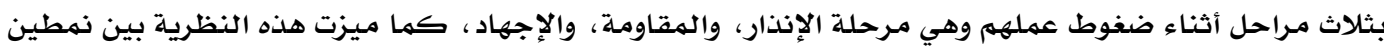
من الضغوط هما: الضغوط السارة والضغوط الغير سارة.

الدراسات السابقة ومناقشتها (ضغوط العمل) وهناك العديد من الدراسات التي تناولت متغير ضغوط العمل منها

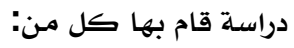

دراسة هللينك (Halling) 2003 كانت بعنوان أسباب الضغوط لدى مديري المدارس الابتدائية الحكومية

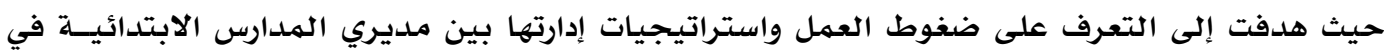

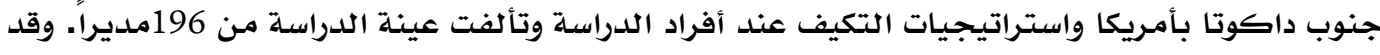
أسفرت الدراسة عن أن ضغوط العمل المتمثلة في كمية العمل، والالتزام بأنظمة وسياسة الولاية

Hammed, S. (2019). Work stress and its relation to educational leadership among school principals. Journal Pon Science Research, 2(3), 331-355. 


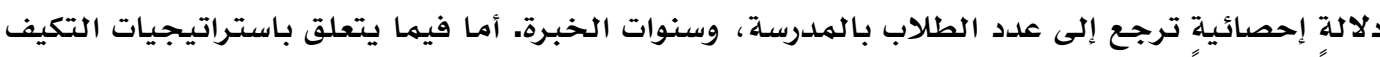

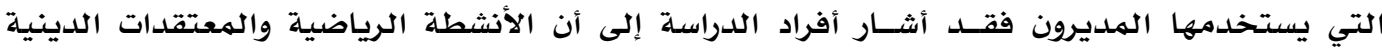

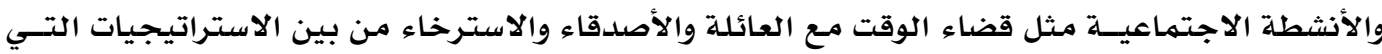
يستخدمونها للتكيف مع الضغوط [14].

دراسة لوكاس (Lucas) 2003 بعنوان عوامل ضغوط العمل كما تراها مديرات المسـارس الثانوية حيث

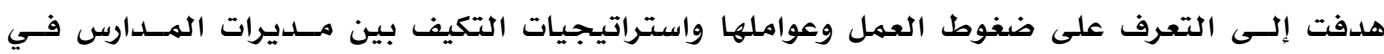

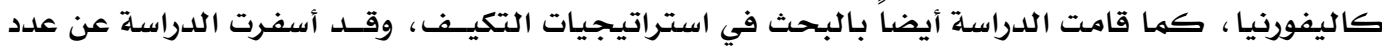

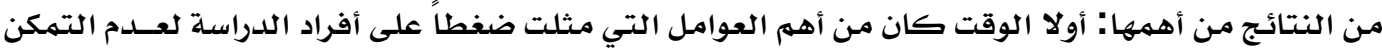

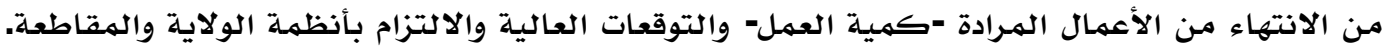

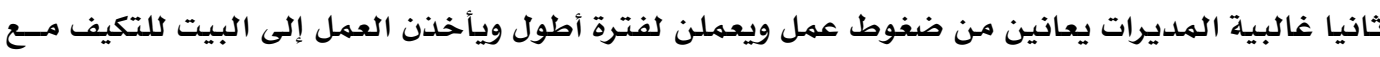
كمية العمل الكبيرة [15].

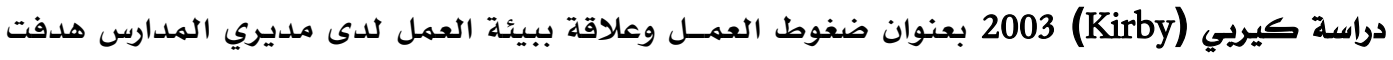

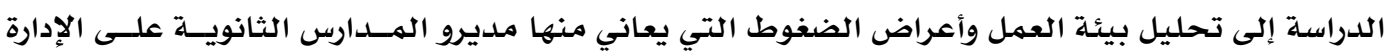

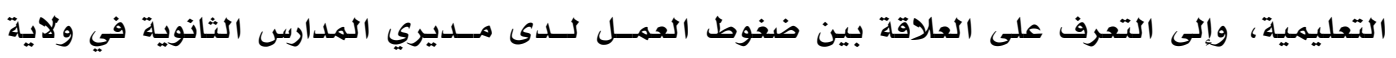

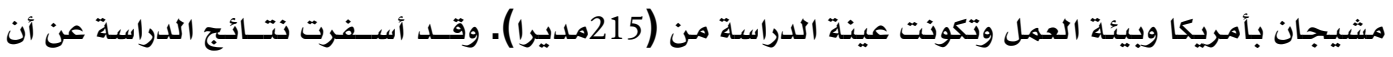

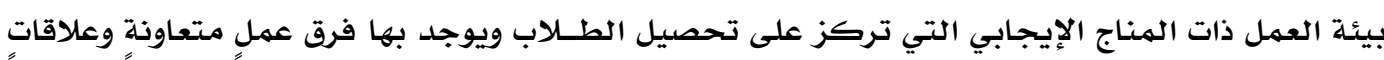

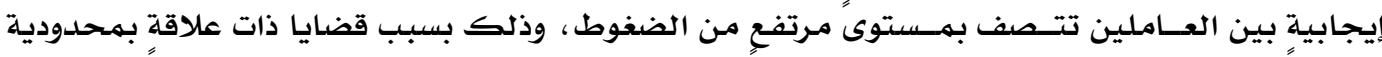

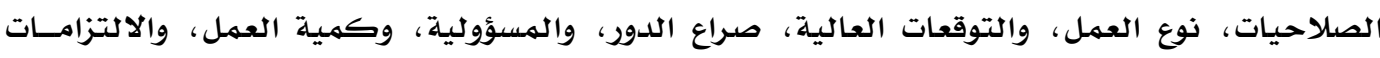

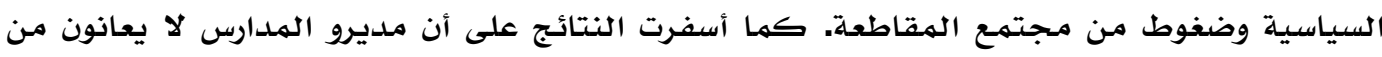

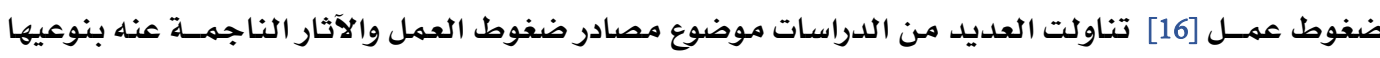

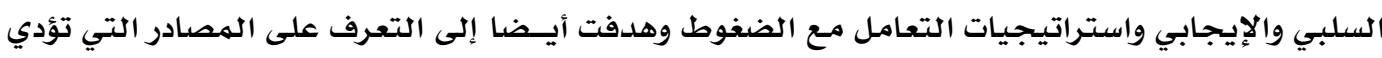

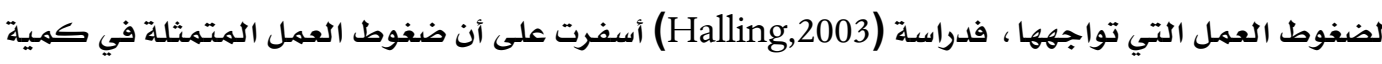

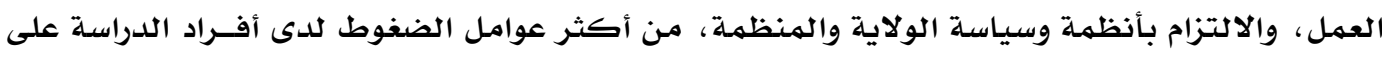

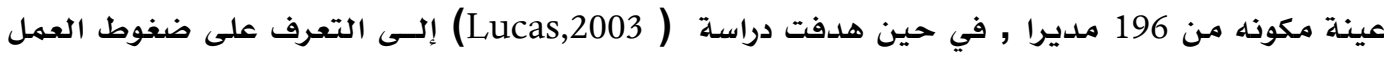

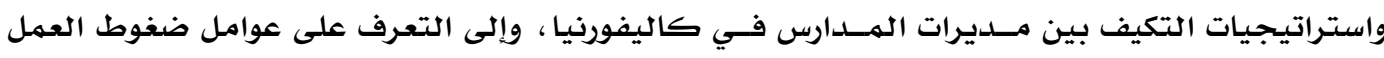

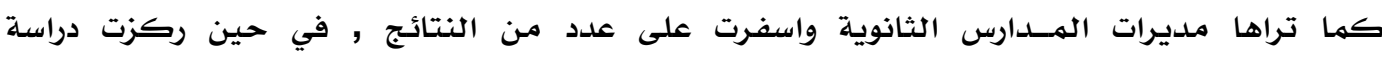
(Kirby,2003)

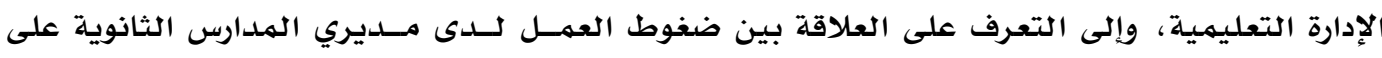

$$
\text { عينة مكونه من 215مديرا. }
$$

\section{Theories of Leadership نظريات القيادة}

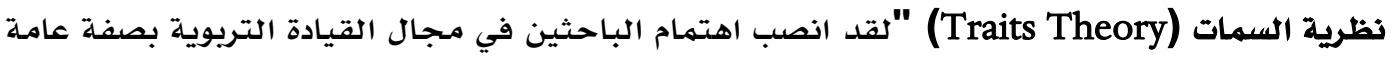

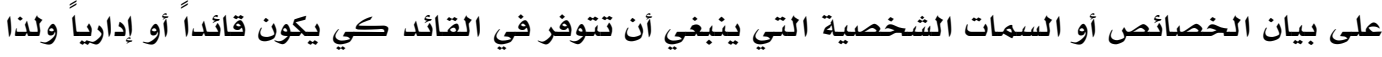

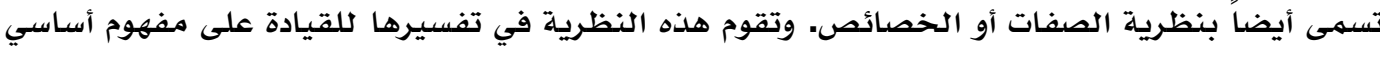

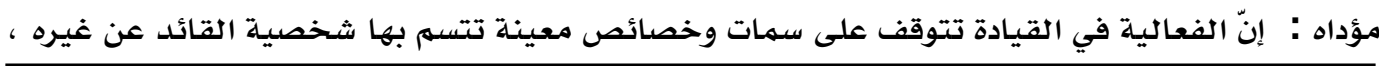
حميد، شهد صبيح. (2019). ضغوط العمل وعلاقته بالقيادة التربوية لدى مديري المدارس. 
كما أن توافر هذه السمات في شخص ما يجعل منه قائداً فعالاً وفي ضوء هذا المفهوم تركزت جهود النها

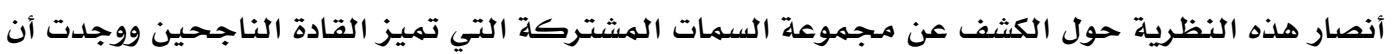

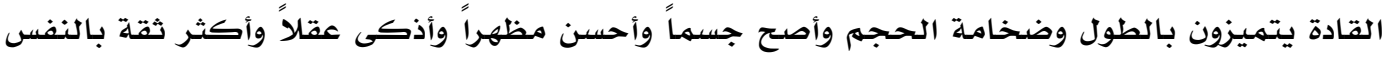

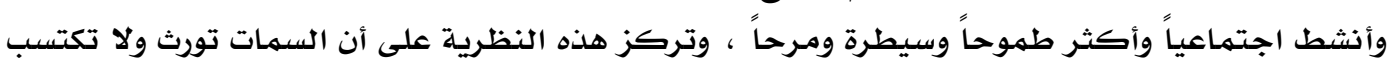

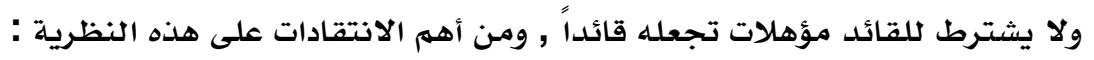
- إن الصفات الشخصية وحدها غير كافية في جعل المدير أو القائد ناجحاً.

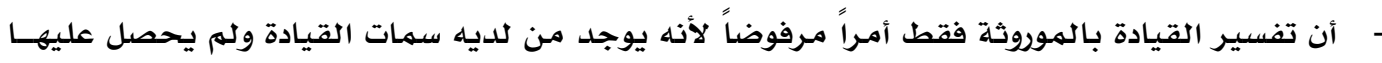

والعكسس صدحيـح [17]

- - يعاب على هذه النظرية أن السمات لا يمكن قياسها نسبياً فهي غير ملموسة.

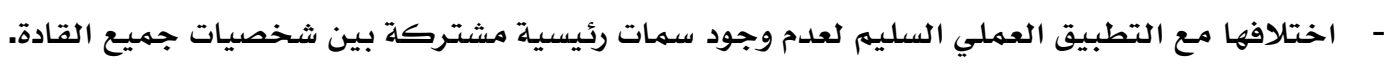
- سمات القائد تختلف باختلاف الجماعة فالسمات التي تصلح لجماعة لا تصلح لغيرها. ثانيا النظرية التفاعلية (The Action Theory) تقوم هذه النظرية على فكرة الامتزاخ والتفاعل بين

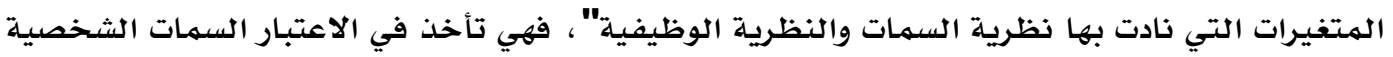

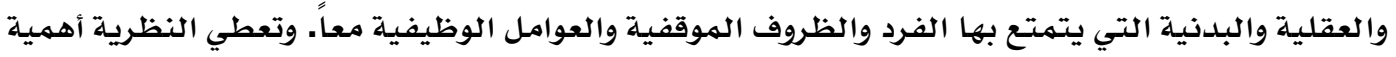

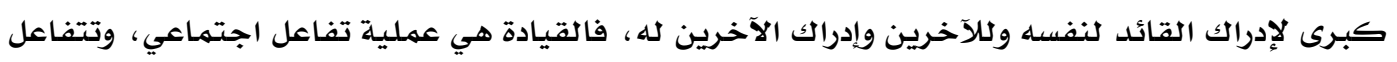
مـع القيادة مجموعة عوامل أساسية لنجاحها أهمها: - خصائص المدير الشخصية مثل الدوافع، التجارب السابقة والتعليه. - خصائص المرؤوسين الشخصية وتشمل الحاجات والدوافع والتوقعات.

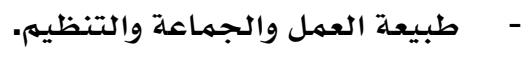

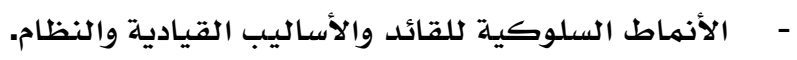
- نتائج الإنتاخ ودوران العمل والدوافع. كما ينبثق عن هذه النظرية الأساليب القيادية التالية: - الأسلوب التوجيهي (Director) وهو معرفة ما هو متوقع من الأفراد وتوجيهـم نحو الهدف.

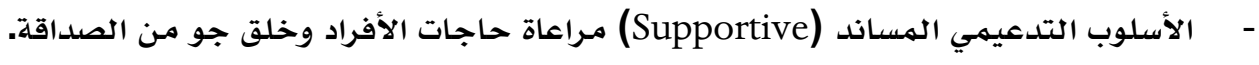

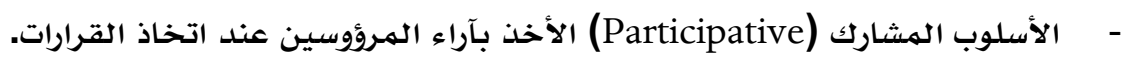

الأسلوب الموجه نحو الإنجاز (Achievement - Oriented) البحث عن طرق تحسين الأداء والتفوق

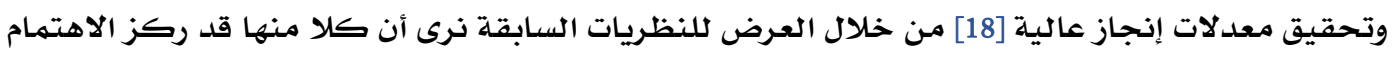
على جانب من جوانب القيادة التربوية حيث أكدت نظرية السمات على أن الفعالية في القيادة تتوقف

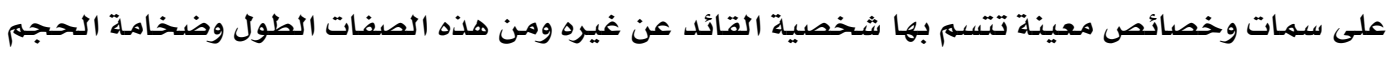
والثقة بالنفس وغيرها من الصفات , وتميل الباحثة في هذه الدراسة لتبني النظرية التفاعلية لجونسون

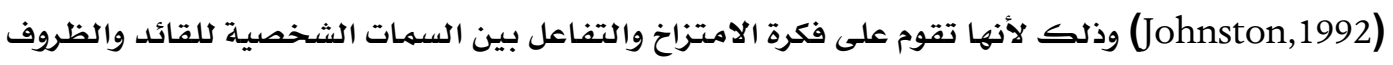
الموقفة المحيطة به والعوامل الوظيفية معا , كما أنها أخذت بعين الاعتبار اساليب القيادة التربوية

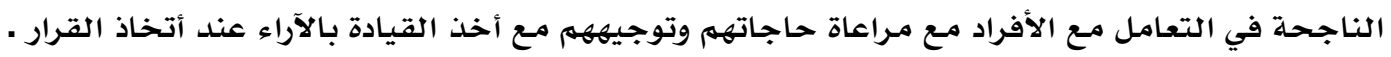

Hammed, S. (2019). Work stress and its relation to educational leadership among school principals. Journal Pon Science Research, 2(3), 331-355. 
j. port. sci. res.
isSN: 2616-7441

الدراسات السابقة ومناقشتها (القيادة التربوية) وهناك العديد من الدراسات التي تناولت متغير القيادة

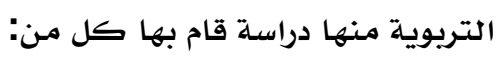

دراسة واشنطن وسوتن وفيلد(Washington ,Sutton, and Field 2006) بعنوان "الفروق الفردية في

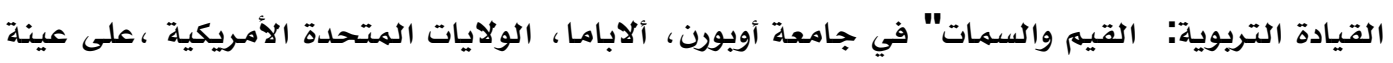

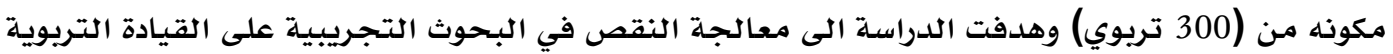

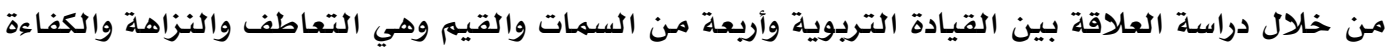

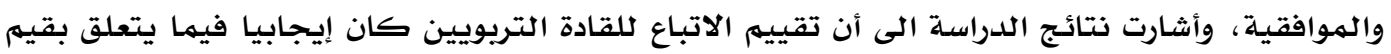
التعاطف والنزاهة والكفاءة، كما كانت إيجابية فيما يتعلق بالموافقية [19].

دراسة أبو تينة رخصاونة رالطحاينة ,2007 بعنوان "القيادة التربوية في المدارس الأردنية كما يدركها

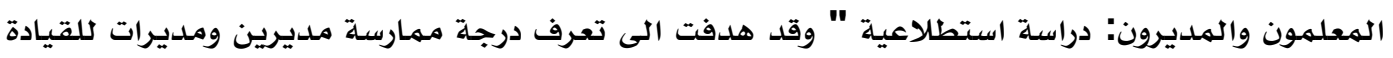

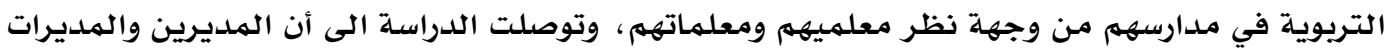

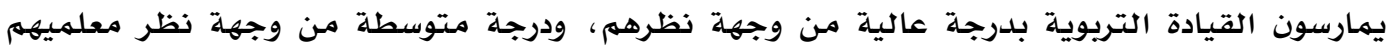

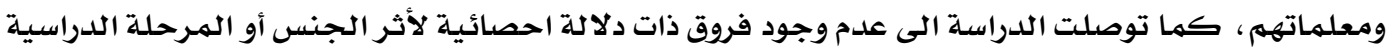

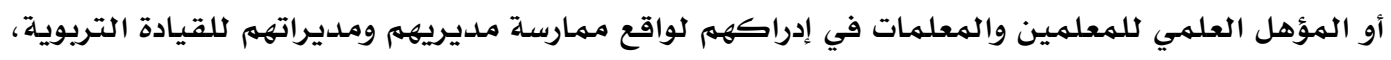

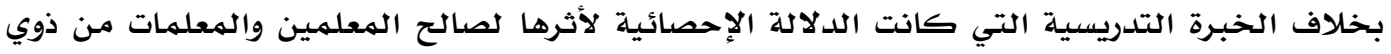
الخبرة الطويل [20].

دراسة سيرات (Serrat) 2009 بعنوان القيادة التربوية والتوتر لدى مديري المدارس حيث هدفت الدراسة

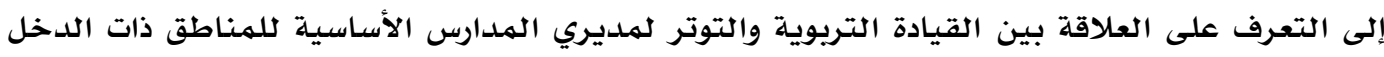

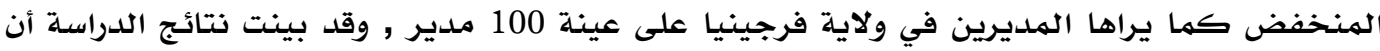

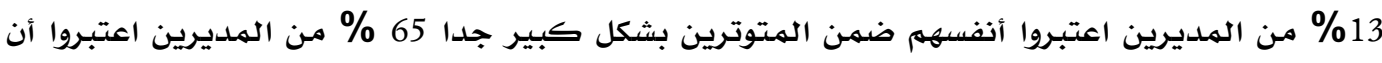

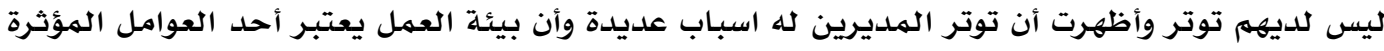

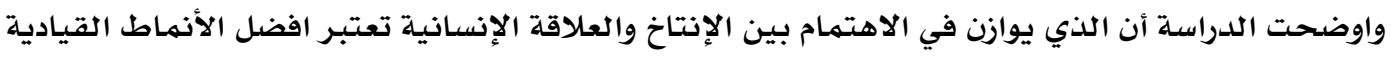
وأقل أثر على توتر مديرو المدارس [21].

دراسة بلاك (Black) 2010 بعنوان "تحليل العلاقة بين القيادة التربوية والمناج المدرسي" في أونتاريو

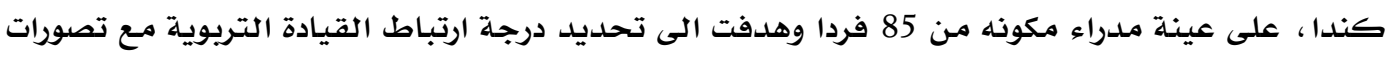

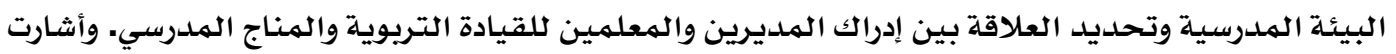

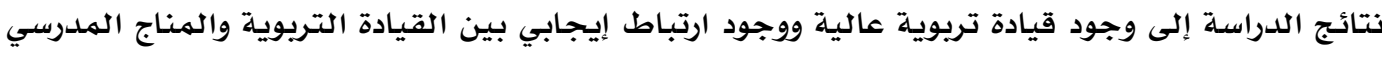

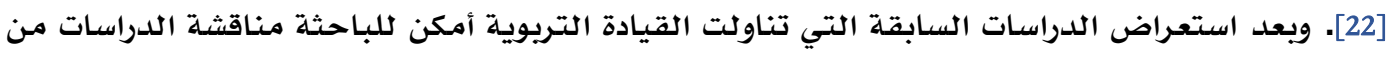

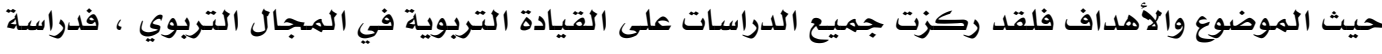

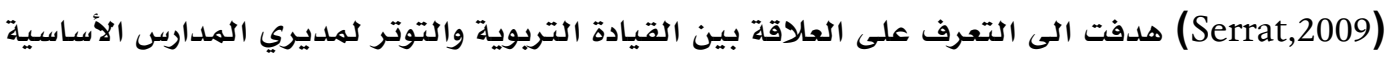

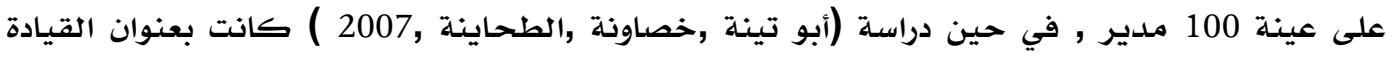

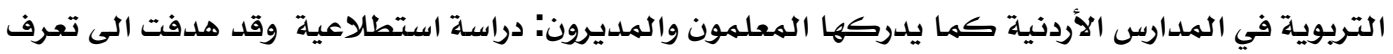

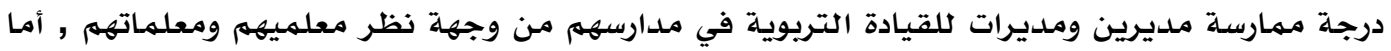

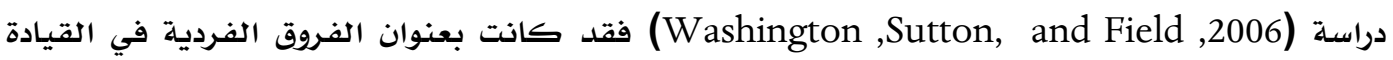

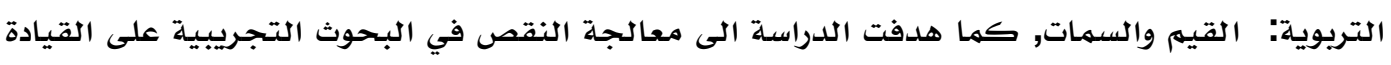
حميد، شهد صبيح. (2019). ضغوط العمل وعلاقته بالقيادة التربوية لدى مديري المدارس. Journal Port Science 355-331 ، (3)2 ، Research 
التربوية من خلال دراسة العلاقة بين القيادة التربوية وأربعة من السمات والقيه وهي التعاطف والنزاهة

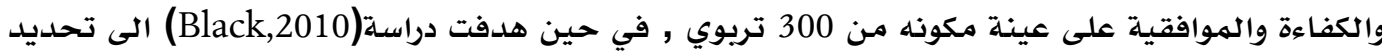

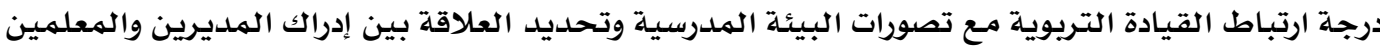

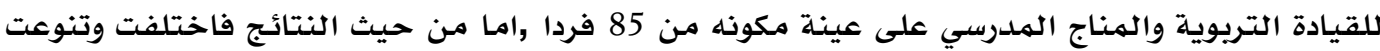
نتائج الدراسات السابقة باختلاف مجتمعاتها واهدافها. 2. المنهجية والإجراءات

إجراءات البحث لقد تناول هذا الفصل تحديد مجتمع البحث واختيار عينة ممثله له، وأداتين للمقياس

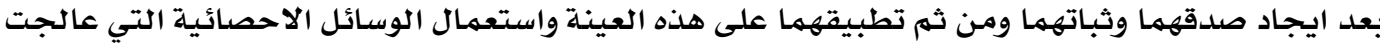
بيانات هذا البحث، وسوف يتم في هذا الفصل استعراض هذه الاجراءات، وعلى النحو الاتي: مجتمع البحث حددت الباحثة مجتمع البحث الحالي بعينة من مديري المدارس الابتدائية والثانوية

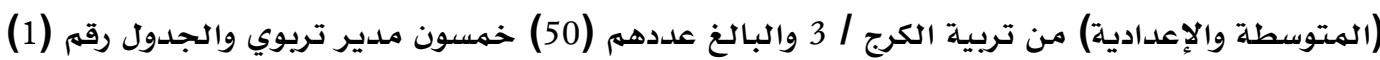
يمثل مجتمع البحث وعينته.

مينة البحث التطبيقية اختارت الباحثة عينة البحث بالطريقة العشوائية لمديري المدارس الابتدائية

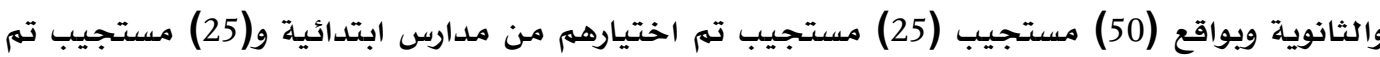

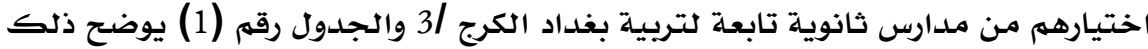

جلدول (1) عينة البحث

\begin{tabular}{|c|c|c|c|c|c|}
\hline اسمى المدرسة & ت & اسمى المدرسة & ت & اسم المدرسة & ت \\
\hline المعرفة & 35 & اعدادية الفوز للبنات & 18 & متوسطة الجوادين للبنات & 1 \\
\hline اشبيلية & 36 & متوسطة الحمزة للبنين & 19 & اعدادية الكاظمية للبنين & 2 \\
\hline البلاذري & 37 & متوسطة المروة للبنات & 20 & متوسطة زين العابدين للبنين & 3 \\
\hline الأنبارين & 38 & ثانوية نور الايمان للبنات & 21 & اعدادية العزة للبنات & 4 \\
\hline الكاظمية & 39 & ثانوية الرياحين للبنات & 22 & ثانوية بابل للبنات & 5 \\
\hline الفتوة & 40 & الشهيد فاضل زيدان الأسود & 23 & اعدادية الأمام الرضا للبنين & 6 \\
\hline الأمام الحسين (ع) & 41 & الرضي & 24 & متوسطة تونس للبنات & 7 \\
\hline القريش & 42 & المواهب & 25 & اعدادية الخطيب للبنين & 8 \\
\hline دار الحكمة & 43 & المعتصم & 26 & ثانوية باب العلم للبنات & 9 \\
\hline شهداء جسر الأئمة & 44 & الهدى & 27 & ثانوية الحسين للبنين & 10 \\
\hline م-المهاجر للبنين & 45 & فلسطين & 28 & ثانوية ذات النطاقين للبنات & 11 \\
\hline ع- ام عمارة للبنات & 46 & السندس & 29 & ثانوية الرواد للبنين & 12 \\
\hline المفيد & 47 & النضال & 30 & ثانوية العقيدة للبنات & 13 \\
\hline مصطفى جواد & 48 & تماضر & 31 & متوسطة الناصر للبنين & 14 \\
\hline الأمام الصادق(ع) & 49 & عاتكة & 32 & متوسطة الزينب للبنات & 15 \\
\hline ث-الخلود للبنات & 50 & عبد المحسن الكاظمي & 33 & ثانوية ام المؤمنين & 16 \\
\hline & & الأمام الحسن (ع) & 34 & ثانوية المستقبل للبنين & 17 \\
\hline
\end{tabular}

Hammed, S. (2019). Work stress and its relation to educational leadership among school principals. Journal Pon Science Research, 2(3), 331-355. 
أداتا البحث من أجل قياس المتغيرين اللذين شملهما البحث الحالي وهما: ضغوط العمل والقيادة التريوية، وجدت الباحثة أن من الأفضل بناء مقياس لضغوط العمل وذلك بالاعتماد على الإطار النظري

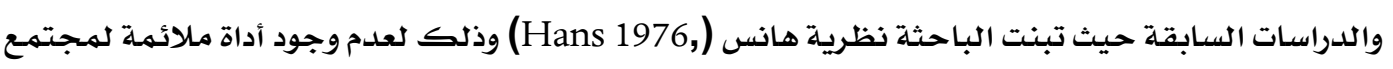
هذا البحث، أما مقياس القيادة التربوية فاستطاعت الباحثة بناء مقياسه وذلك بالاعتماد ايضا على العادئ الإطار النظري والدراسات السابقة حيث تبنت الباحثة النظرية التفاعلية لجونسون (Johnston,1992) وفيما يأتي عرض لكيفية بناء الأداتين.

الأداة الأولى بناء مقياس ضغوط العمل بهدف بناء مقياس ضغوط العمل قامت الباحثة بالخطوات الأتية 1) تحديد الإطار النظري لقد قامت الباحثة بتبني نظرية هانس (Hans 1976).

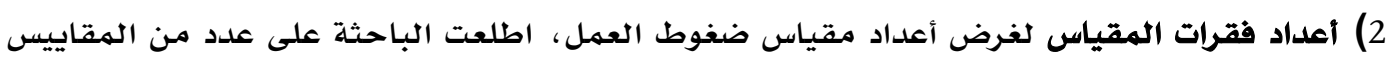

$$
\text { التي أعدت لهذا الغرض، وهي }
$$

A . مقياس Lucas) تألف هذا المقياس من (60) فقرة تقيس ضغوط العيس العمل واستراتيجيات التكيف بين مسديرات المسدارس فـي كاليفورنيا، وعوامل ضغوط العمل كما تراها مديرات

$$
\text { المسـارس الثانوية وامام كل فقرة بديلين (أحيانا ، استمرار). }
$$

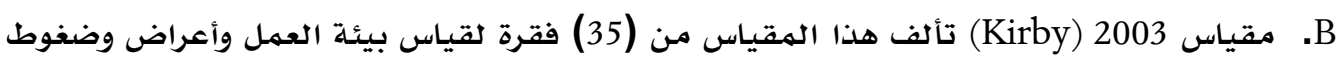

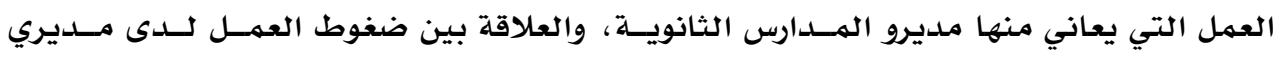

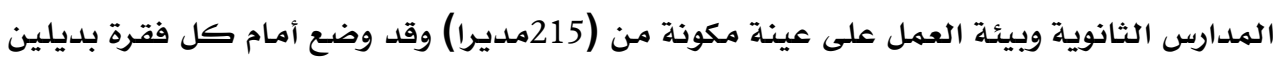

$$
\text { (نعم، لا أبدا). }
$$

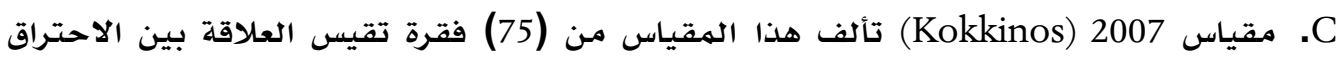

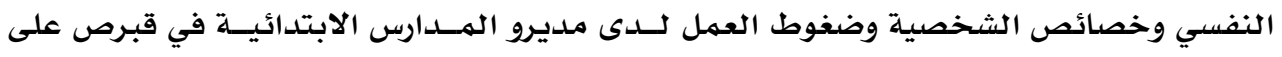

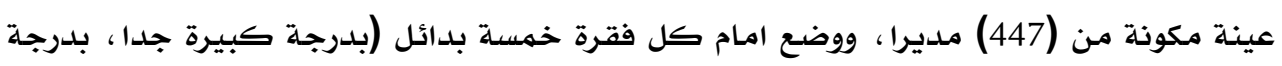

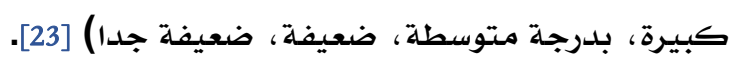

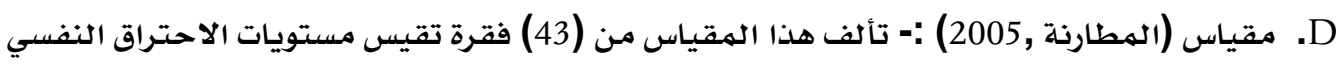

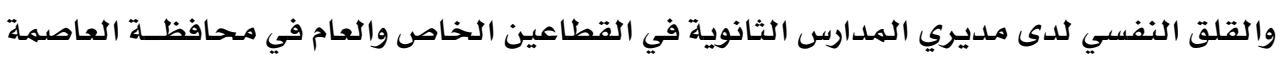

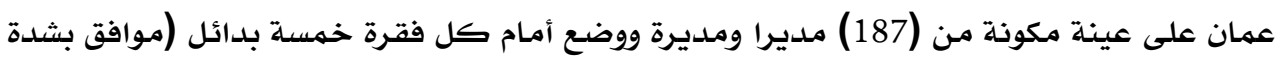

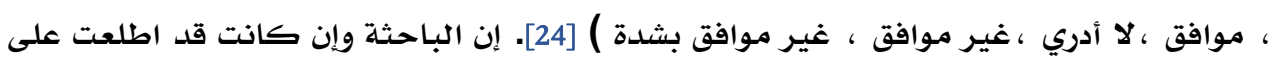

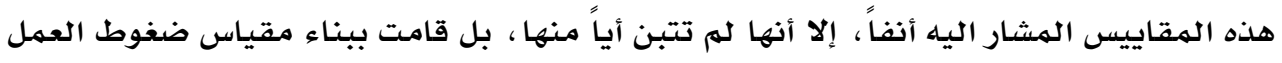

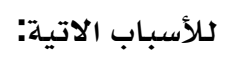

$$
\text { o إن هذه المقاييس غير واضحة في إعطاء الدرجات لأوزان بدائلها. }
$$

O ان هذه المقاييس قد اعتمدت على نظريات اخرى غير نظرية هانس Hans التي تم

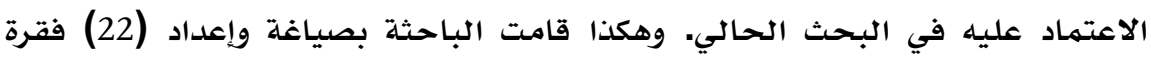

حميد، شهد صبيح. (2019). ضغوط العمل وعلاقته بالقيادة التربوية لدى مديري المدارس. Journal Port Science ، 
بالاعتماد على الإطار النظري والدراسات السابقة، والجدول (2)، يبين أرقام الفقرات

والمصادر العلمية التي اعتمدتها الباحثة في أعداد فقرات مقياس ضغوط العمل.

جدول (2) فقرات مقياس ضغوط العمل ومصادرها

\begin{tabular}{|c|c|}
\hline المصدر & أرقام الفقرات \\
\hline (Hans,1976, p.p112-118) & $1,3,4,13,14,16,17,18,21$ \\
\hline (Lucas,2003, p.231) & $2,9,20$ \\
\hline (Kirby,2003, p.333) & 6,15 \\
\hline (Kokkinos,2007, p.112) & $7,10,12,22$ \\
\hline (المطارنه,2005,ص.21) & $5,8,11,19$ \\
\hline
\end{tabular}

الأداة الثانية بناء مقياس القيادة التريوية

1) الحديد الإطار النظري: لقد قامت الباحثة بتبني النظرية التفاعلية لجونسون (Johnston,1992). 2) لغرض أعداد مقياس القيادة التربوية، اطلعت الباحثة على عدد من المقاييس التي أعدت لهذا

A. مقياس (Serrat, 2009) يتألف من (64) فقرة لفحص انماط القيادة التربوية على عينة 100 مدير تكون الاجابة عليها وفق طريقة ديكارت (التدريج الخماسي) (دائما ، غالبا ، احيانا ، نادرا،

$$
\text { لا ابدا) (21). }
$$

B مقياس (Washington, Sutton, and Field 2006) يتكون هذا المقياس من (40) سؤالا، تكون الإجابة عنها ب (نعم أو لا) على عينة مكونه من (300تربوي) ، (20) من هذه الأسئلة تمثل

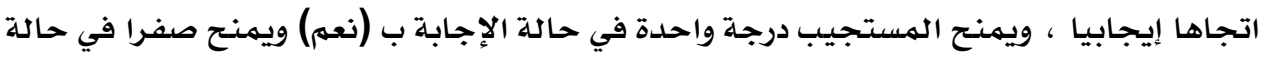

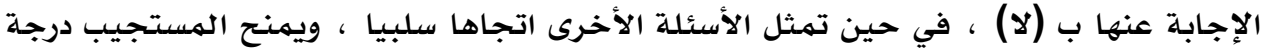

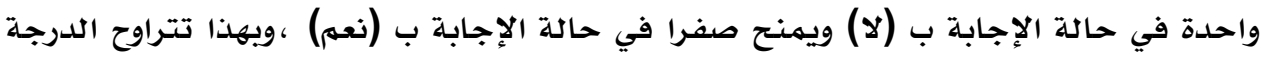

$$
\text { الكلية لالإجابة عن المقيس بين (صفر-40). }
$$

C. مقياس ( Black,2010) يتكون هذا المقياس من (70) فقرة لقياس القيادة التربوية وتحليل

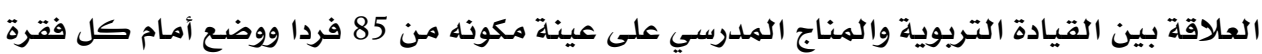

$$
\text { ثلاث بدائل (دائما , أحيانا , لا أبدا). }
$$

إن الباحثة وإن كانت قد اطلعت على هذه المقاييس، فأنها لهم تتبن أيا منها بل قامت ببناء مقياس القيادة التربوية وللأسباب الآتية.

1) إن المقاييس كانت غير واضحة في إعطاء الدرجات عند عملية التصحيح.

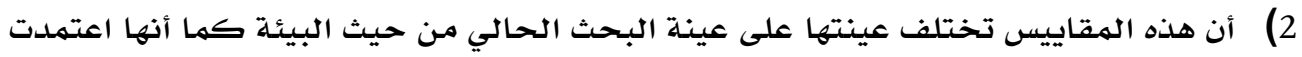

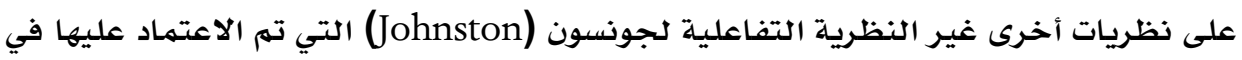

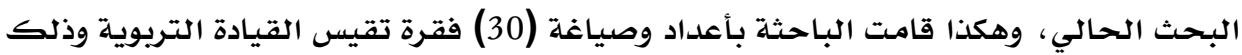


بالاعتماد على الإطار النظري والدراسات السابقة، والجدول (3) يوضح مصادر فقرات مقياس

$$
\text { القيادة التريوية. }
$$

جدول (3) فقرات مقياس القيادة التربوية ومصادرها

\begin{tabular}{|c|c|}
\hline المصدر & أرقام الفقرات \\
\hline (Johnston, 1992, p.p 127-144) & $2,4,7,8,13,14,16,18,20,22,23,25,27$ \\
\hline (Serrat, 2009, p.p.11-13) & $3,9,10,15,24,28$ \\
\hline (Washington, Sutton, and Field,2006, p.341) & $5,11,17,19$ \\
\hline (Black,2010, p.465) & $1,6,12,21,26$ \\
\hline
\end{tabular}

مؤشرات الصدق (Validity Indicates) إن مفهوم الصدق (Validity) وإن كان يعدَ من المفاهيه

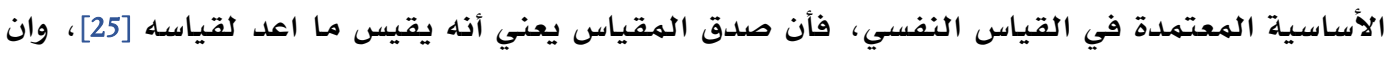

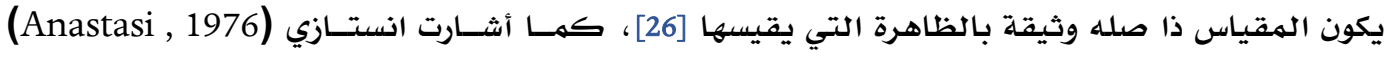
في هذا الصدد إلى إن الصدق هو تجميع للدلالة التي نستدل بها على قدرة المقياس على قياس ما اعد العداس لقياسه [27]، وقد تحقق في المقياس الحالي الصدق الظاهري (Face Validity) وكما النحو الاتي: الصدق الظاهري (Face Validity) لقد بين ( Aiken , 1979 ) أن الصدق الظاهري لأي مقياس يتحقق

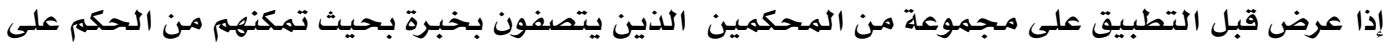

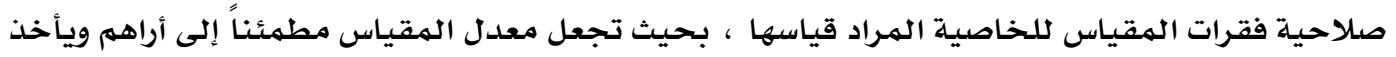
بالأحكام التي يتفق عليها معظمهم [28]، وهكذا فقد تحقق للباحثة هذا النوع من أنواع الصدق من خلال عرض فقرات المقياسين وتعليماتهما وطريقة تصحيحهما على مجموعة من المحكمين (*) المختصين الذين حصلت موافقتهم على صلاحية فقرات الهقياسين وبدائلهما وطريقة تصحيحهما و ملاءمتهما

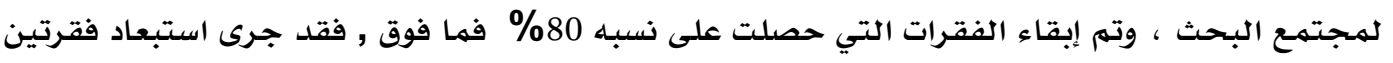

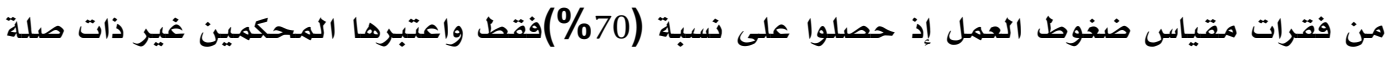
بضغوط عمل مدير المدرسة في حين وافقوا على استبقاء (20) فقرة وبنسبة 85\% فأعلى , في حين تم استبعاد فقرتين ايضا من فقرات مقياس القيادة التربوية واعتبرها المحكمين انها طويلة من حيث الصياغة

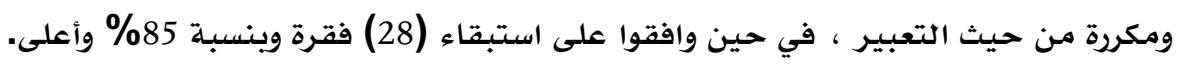
تصحيح المقياس وضعت الباحثة درجة الاستجابة لكل مستجيب على كل فقره من فقرات المقياس

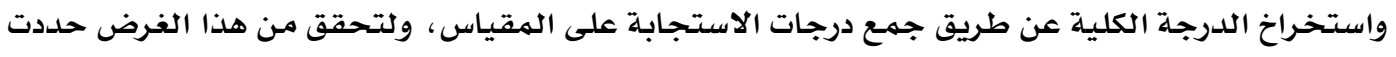
الباحثة لكل فقره وعلى يسارها خمسة بدائل وقد تم تصحيح إجابات المستجيب على فقرات مقياس

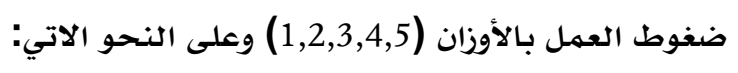

\begin{tabular}{|c|c|c|c|c|c|}
\hline غير موافق بشده & غير موافق & أحيانا & موافق & موافق بشده & البدائل \\
\hline 1 & 2 & 3 & 4 & 5 & الدرجات \\
\hline
\end{tabular}

جدول (4) بدائل مقياس ضغوط العهل وأوزانه

حميد، شهد صبيح. (2019). ضغوط العمل وعلاقته بالقيادة التربوية لدى مديري المدارس. Journal Port Science 355-331 ، (3)2 Research 
وبذلك تبلغ أعلى درجه للمستجيب على مقياس ضغوط العمل (100) وأقل درجه يحصل عليها المستجيب

1) الأستاذ الدكتورة بثينة منصور الحلو / كلية الآداب / جامعة بغداد.

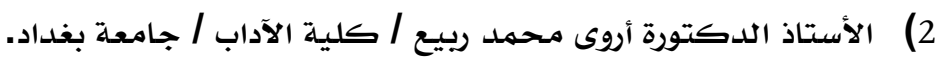

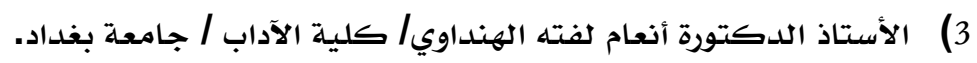

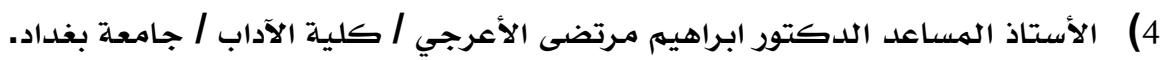

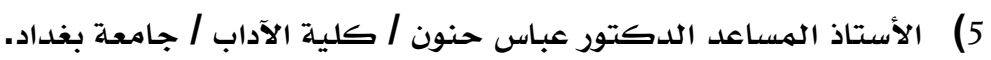

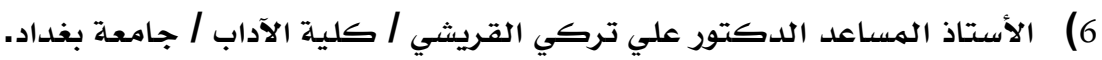

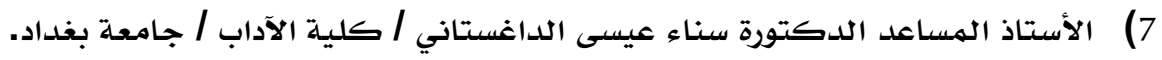

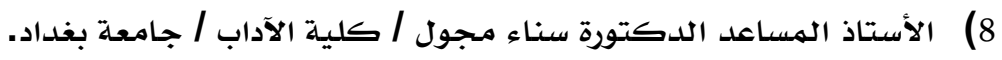

9) الدكتورة أسراء عباس هادي / تربية الكرج الثالثة / وزارة التربية العراقية.

10) الست شفاء رحمن عبد الله امشرف اختصاصي أداري / تربية الكرج الثالثة.

كما وضعت الباحثة درجة الاستجابة على مقياس القيادة التربوية لكل مستجيب وعلى كل فقرة من

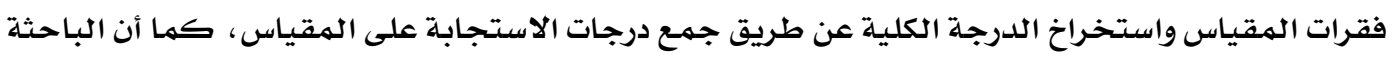
حددت لكل فقرة ثلاث بدائل وقد تم تصحيح إجابات المستجيب على فقرات مقياس القيادة التربوية

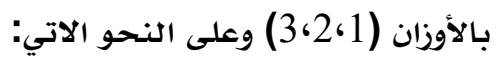

جدول (5) بدائل مقياس القيادة التريوية واوزانه

\begin{tabular}{|c|c|c|c|}
\hline لا ابدا & احيانا & دائما & البدائل \\
\hline 1 & 2 & 3 & اللدرجات \\
\hline
\end{tabular}

وبذلك تبلغ أعلى درجه للمستجيب على مقياس القيادة التربوية (84) وأقل درجه يحصل عليها المستجيب

مؤشرات الثبات (Rialability Indicates) إن مفهوم الثبات وإن كان يتمثل بالدقة والاتساق في أداء الإفراد والاستقرار في النتائج عبر الزمن، فأن الاختبار الثابت يعطي النتائج نفسها إذا طبق على المجموعة

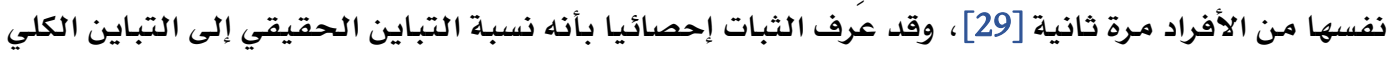

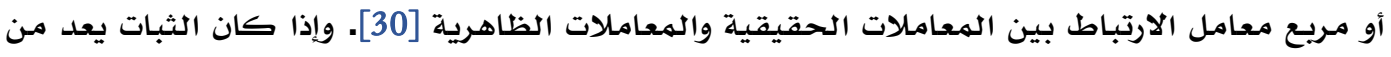
الخصائص السايكومترية المهمة للمقاييس النفسية، والذي يشير الى أتساق درجات المقياس، في قياس

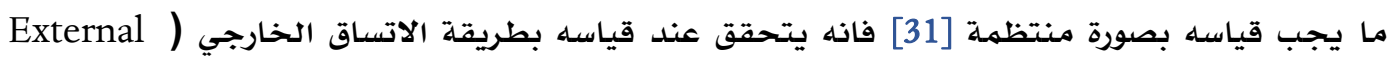

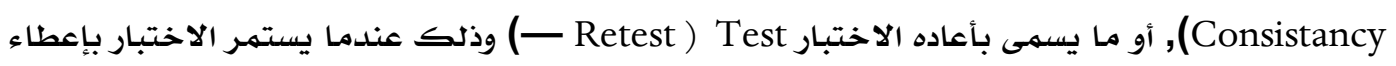
نتائج ثابتة بتكرار تطبيقه عبر الزمن , كما أن قياس الثبات بالاتساق الداخلي ( Internal

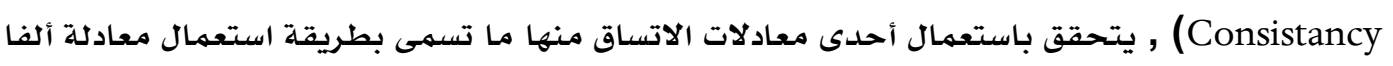
Hammed, S. (2019). Work stress and its relation to educational leadership among school principals. Journal Pon Science Research, 2(3), 331-355. 
كرونباج , والذي يمكن تحقيقه من خلال كون فقرات الاختبار جميعها تقيس المفهوم نفسه في المدة

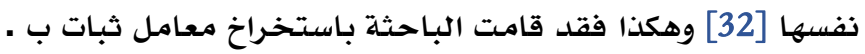

طريقة الاختبار وأعادة الاختبار (Test-Retest Method) يسمى معامل الثبات المستخرخ بهذه الطريقة بمعامل الاستقرار (Stability) عبر الزمن، والذي يتطلب اعادة تطبيق الاختبار على عينة الثبات نفسها بعد مرور اسبوعين من الزمن، وحساب معامل الارتباط بين درجات التطبيق الأول والثاني [33] ولهذا فان معامل الارتباط العالي في عينة الثبات يشير الى وجود استقرار في إجابات الأفراد عبر الزمن [34] ولقد قامت الباحثة بتطبيق مقياس ضغوط العمل والقيادة التربوية باستعمال هذه الطريقة على عينه مكونه

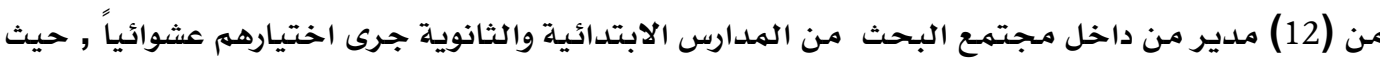

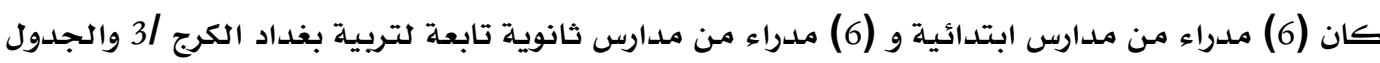

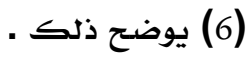

جلدول (6) عينة ثبات مقياس ضغوط العمل والقيادة التريوية

\begin{tabular}{|c|c|c|c|}
\hline المدرسة & $=$ & المدرسة & ت \\
\hline مصطفى جواد & 7 & ثال بابل للبنات & 1 \\
\hline دار الحكمة & 8 & ث/ الحسين للبنين & 2 \\
\hline الكاظمية & 9 & ع/ العزة للبنات & 3 \\
\hline الأمام الحسين (ع) & 10 & ع/الخطيب للبنين & 4 \\
\hline الرضي & 11 & م/ الجوادين للبنات & 5 \\
\hline عبد المحسن الكاظمي & 12 & م/ الناصر للبنين & 6 \\
\hline
\end{tabular}

وهكذا قامت الباحثة بعد مرور أسبوعين من التطبيق الأول للمقياسين بأعاده التطبيق مره أخرى وعلى

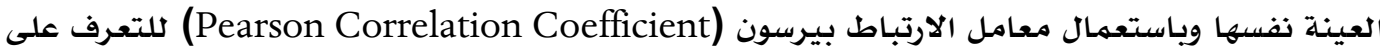
طبيعة العلاقة بين درجات التطبيق الأول والثاني [35] وقد ظهر ان معامل الثبات لضغوط العمل ظهر

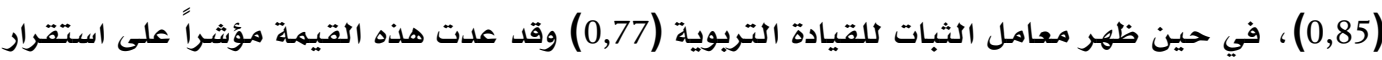

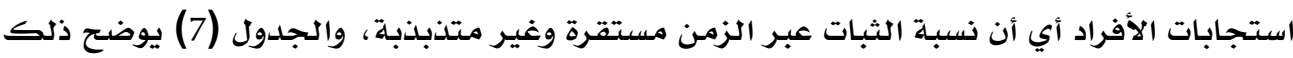
جلسول (7) ثبات مقياس ضغوط العهل والقيادة التريوية بطريقة أعادة الاختبار

\begin{tabular}{|c|c|c|}
\hline معامل الثبـات & المقياس & ت \\
\hline 0,85 & ضغوط العمل & 1 \\
\hline 0,77 & القيادة التريوية & 2 \\
\hline
\end{tabular}

لتحليل ومعالجـة بيانات هذا البحث، فقد استعملت الوسائل الاحصائية الآتية: 1- الاختبار التائي لعينـة واحدة (T. test-Sample Case) [36]، وقد استعمل لقياس ضغوط العمل والقيادة التربوية لدى أفراد 
معامل الارتباط بيرسون (Pearson Correlation Coefficient) [37]، وقد استعمل في إيجاد العلاقة

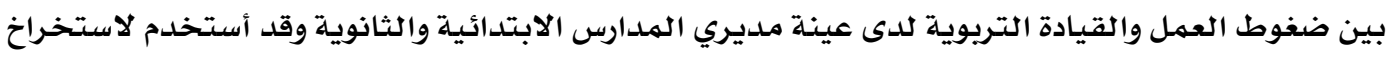
الثبات بأعاده الاختبار لمقياس كل من ضغوط العمل والقيادة التربوية.

$$
\text { 3. التحليل وعرض النتائج }
$$

بعد تحليل البيانات ومعالجتها احصائيا قامت الباحثة في هذا الفصل باستعراض النتائج التي توصلت إليها ، استنادا الى ما تم جمعه من بيانات على وفق تسلسل أهداف البحث، وفي ضوء هذه النتائج خرجت

$$
\begin{aligned}
& \text { الباحثة بالعديد من التوصيات، وقد استعرضت هذه الإجراءات وعلى النحو الآتي } \\
& \text { اولا عُعرض النتائج عُرضت نتائج هذا البحث وعلى النحو الآتي }
\end{aligned}
$$

تعرف مستوى ضغوط العمل للى مديري المدارب تحقيقاً للهدف الاول وبعد جمع البيانات المحصلة

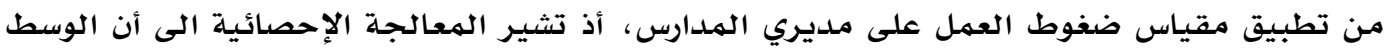

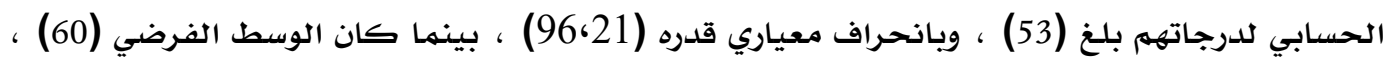

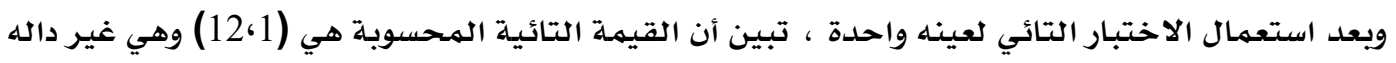

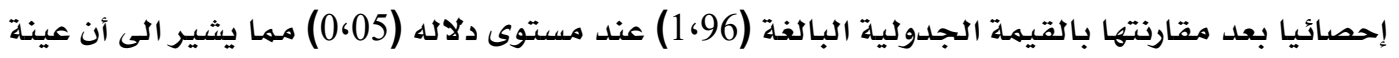

\begin{tabular}{|c|c|c|c|c|c|c|c|}
\hline مستوى الدلالة & القيمة التائية & القيمة التائية & الفرضطي & الانحراف & الحسطابي & العدد & المتغير \\
\hline غير داله عند & $96 \cdot 1$ & $12 \cdot 1$ & 60 & $96 \cdot 21$ & 53 & 50 & ضغوط العمل \\
\hline
\end{tabular}

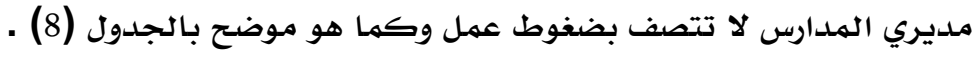
جلدول (8) الوسط الحسابي والانحراف المعياري والوسط الضرضي والقيمة التائية المحسوبة والجلدولية لعينة مديري

تعرف مستوى القيادة التريوية لدى مديري المدارس تحقيقاً للهدف الثاني وبعد جمع البيانات المحصلة من تطبيق مقياس القيادة التربوية على مديري المدارس، أذ تشير المعالجة الإحصائية الى أن الوسط لمأل

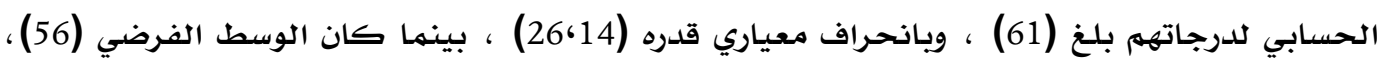

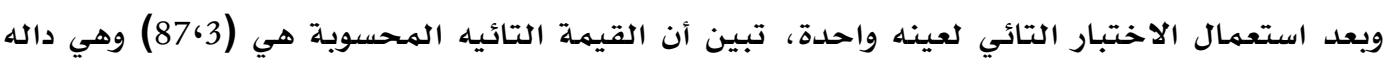

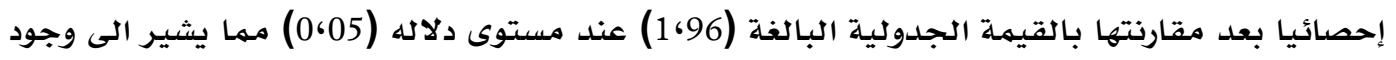
قيادة تربوية ناجحة لدى مديري المدارس اي أن عينة البحث تتصف بقيادة تربوية عالية ـ وكما هو موضح في الجدول (9). 
جلسول رقه (9) الوسط الحسابي والانحراف الهعياري والوسط الفرضي والقيمة التائية الهحسوبة والجلسولية لعينة ملديري

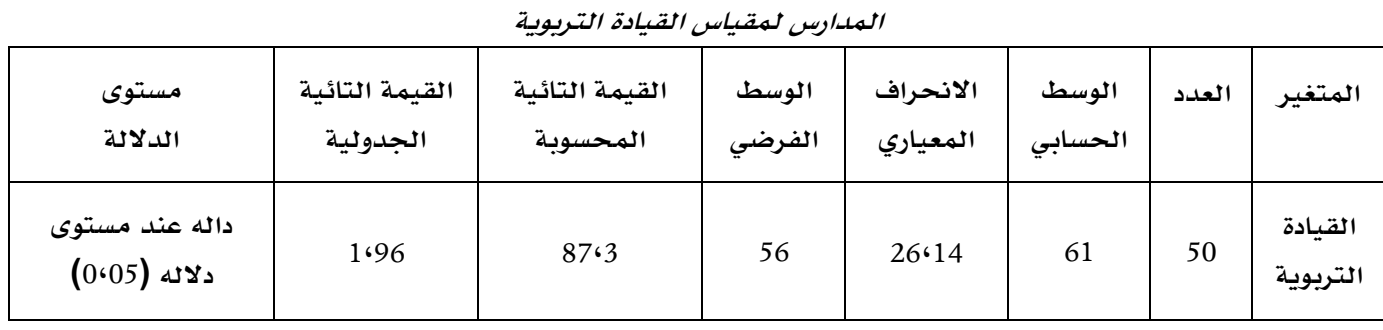

تعرف طبيعة العلاقة بين ضغوط العمل والقيادة التريوية لدى مديري المدارس من أجل التعرف الى طبيعة العلاقة بين ضغوط العمل والقيادة التربوية لدى مديري المدارس قامت الباحثة بتطبيق معامل ارتباط

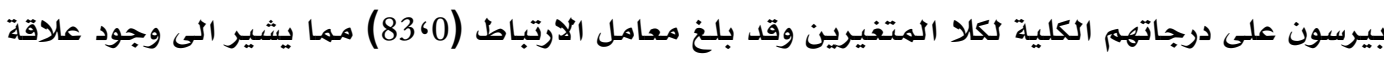
ارتباطية عكسية بين المتغيرين اي كلما أنخفض مستوى ضغوط العمل لدى مديري المدارس أرتفع مستوى القيادة التريوية لديهم والعكس صحيح. تفسير ومناقشة النتائج

فيما يتعلق بالهدف الأول الذي يشير الى ان مديري المدارس لا يعانون من ضغوط عمل, فقد اتفقت هذه

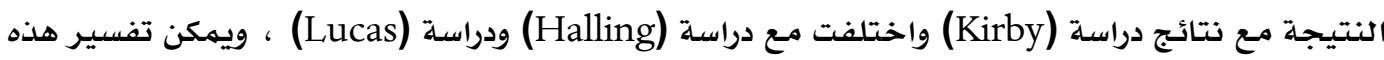

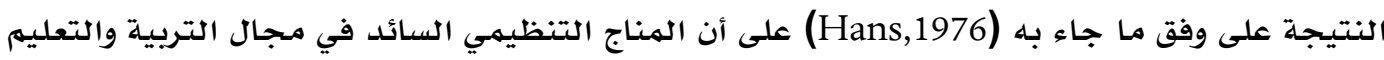
في المؤسسات التربوية جيد مثل كثرة المشاركة في أتخاذ القرارات مع أعطا صلاحيات تساعد على لى لفي

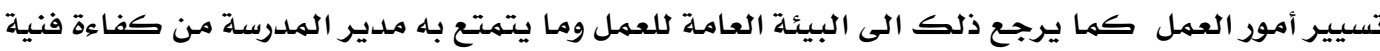
ووعي وفطنه تساعد في التصدي للمشكلات ومواجهتها والتغلب عليها ومهارات وظيفية، فنية، سلوكية، فكرية مما يساعد ذلك في خفض نسب ضغوط العمل لدى مدير المدرسة في البيئة. فيما يخص نتيجة الهدف الثاني الذي يشير الى وجود قيادة تربوية ناجحة ذات مستوى مرتفع لدى مديري

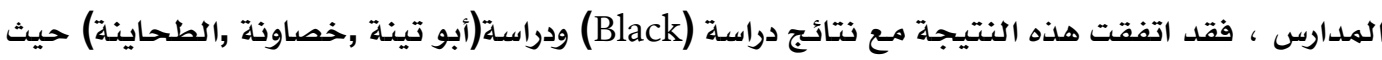
افادت نتائجهما على وجود قيادة تريوية عالية لدى مدراء المدارس ، ويمكن تفسير هذه النتيجة وعلى وفق

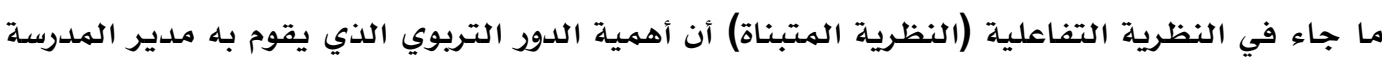
والذي يقدمها وماله من تأثير مباشر على العاملين في المدرسة ومراعاة حاجات الأفراد وماله من فعاليات في تخطيط وتنظيم وتنسيق وتوجيه ومتابعة كل نشاط يقوم به العاملين فهو المشرف المقيم داخل المدرسة وهو المسؤول عن توجيه الأمور والأعمال والأثراف عليها ومراقبة الأداء وسيطرته على المتغيرات المحيطة به ولأيمكن ان يقوم بهذا الدور التربوي الفعال الا من تتوافر فيه سمات عقلية وشخصية وبدنية وكفاءة ذاتية تؤهله للقيام بهذه الأعباء داخل البيئة المدرسية كل تلك السمات والمواقف تجعل منه

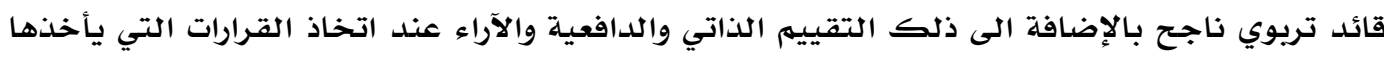
من المرؤوسين من مشرفين والتعاون المستمر فيما بينهم في تطبيق التعليمات والأنظمة أي لا توجد هناك حلقة مفرغه في العمل كل ذلك يعد بهثابة دافع ومحفز له في عمله بأن يصبح قيادي تربوي.

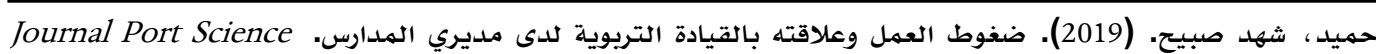


وجود علاقة ارتباطية عكسية بين ضغوط العمل والقيادة التربوية فقد اتفقت هذه النتيجة مع نتائج دراسة

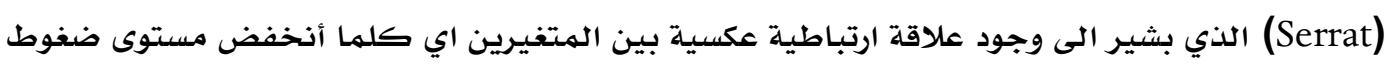
العمل لدى مديري المدارس أرتفع مستوى القيادة التربوية لديهم والعكس صحيح.

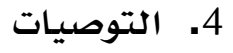

من نتائج البحث والتي يمكن اعتبارها تجسيد لواقع حال المجتمع أمكن للباحثة وضع بعض التوصيات في ضوء النتائج التي توصل اليها البحث الحالي، يمكن للباحثة ان توصي بما يأتي:

1) تنمية وتدعيم القوى الإيجابية لمديري المدارس في المؤسسات التربوية وتقليص الجوانب السلبية

قدر الإمكان ومواكبة المتغيرات المحيطة وتوظيفها لخدمة العملية التربوية وحسم الخلافات

$$
\text { والترجيح بين الآراء. }
$$

2) تنظيم دورات تدريبية لمديري المدارس عن أهداف واساليب وانماط القيادة التريوية مـع الاهتمام

$$
\text { بالتخطيط والأعداد لتلك البرامج. }
$$

3) الاهتمام بتحديث نظم الإدارة المدرسية في المدارس بحيث تعطي صلاحيات الى مدير المدرسة تمكنه

من ايجاد مناج عمل جيد، يؤدي الى تنمية قدراته في التعامل مـع ضغوط العمل.

$$
\text { 5. - 5 المقترحات }
$$

استكمالا لمتطلبات البحث الحالي، فأن الباحثة تقترح إجراء دراسات وبحوث لاحقه تتناول

علاقة القيادة التربوية بمتغيرات اخرى لم يتناولها البحث الحالي كمستوى الرضا الوظيفي.

علاقة الضغوط النفسية لمديري المدارس بمتغيرات اخرى لم يتناولها البحث الحالي كمتغيرات

الشخصية التي تتعلق بالسن والخبرة.

\section{References}

[1] Al-Sayad, H. Ibrahim, H. Ahmed, A. (1989). البناء العاملي لأنماط القيادة التريوية وعلاقة هذه الانماط بالرضا Riyad: Arab Education Office Gulf States P (17), Sixth year. https://search.mandumah.com/Record/10082

[2] Shaunessy, E., \& Suldo, S. M. (2010). Strategies used by intellectually gifted students to cope with stress during their participation in a high school international baccalaureate program. Gifted Child Quarterly, 54(2), 127-137. https://doi.org/10.1177/0016986209355977

[3] Askar, Ali and Abdullah Ahmed. (1997) مدى تعرض العاملين لضغوط العمل في بعض المهن وعلاقتها ببعض متغيرات الشخصية>. Egyption Journal of psychological studies the number. 7(16).

[4] Tareeri, A. (1994). الضغط النفسي مفهومه تشخيصه طرق علاجه ومقاومته> Al-Ryadh. http://www.gulfkids.com/ar/book14-2803.htm

Hammed, S. (2019). Work stress and its relation to educational leadership among school principals. Journal Pon Science Research, 2(3), 331-355. 
[5] Moran, D. S. (2015). A study of perceived levels of job related stress for school principals in a school district in Southeast Louisiana. Dissertation Abstracts International Section A: Humanities and Social Sciences. ProQuest Information \& Learning. Retrieved from http://search.ebscohost.com/login.aspx?direct=true\&db=psyh\&AN=2015-99171-

$\underline{073 \& \text { site }=\text { ehost-live }}$

[6] Noor Hamdan, A. F., \& Othman, S. Z. (2011). Job Stress Among Secondary School Teacher: A Study in District of Perak Tengah, Perak Darul Ridzuan. College of Business, Master of. Retrieved from http://etd.uum.edu.my/2795/2/1.Anwar Faiz Noor Hamdan.pdf

[7] Gmelch, W. H., \& Gates, G. (1998). The impact of personal, professional and organizational characteristics on administrator burnout. Journal of Educational Administration, 36(2), 146-159. https://doi.org/10.1108/09578239810204363

[8] Ibrahim, L. (1994). عمليات تحمل الضغوط في علاقتها بعدد من المتغيرات النفسية لدى المعلمين. Qatar University, Journal of the Center for Educational Research. https://qspace.qu.edu.qa/handle/10576/8110

[9] Chemers, M. M. (2000). Leadership research and theory: A functional integration. Group Dynamics. Educational Publishing Foundation. https://doi.org/10.1037/1089-2699.4.1.27

[10] Goldenberg, D., \& Waddell, J. (1990). Occupational stress and coping strategies among female baccalaureate nursing faculty. Journal of Advanced Nursing, 15(5), 531-543. https://doi.org/10.1111/j.1365-2648.1990.tb01852.x

[11] Weick, K. E. (1984). Behavior in Organizations: Understanding and Managing the Human Side of Work. PsycCRITIQUES, 29(9). https://doi.org/10.1037/023221

[12] Willower, D. J. (1994). Dewey's Theory of Inquiry and Reflective Administration. Journal of Educational Administration, 32(1), 5-22. https://doi.org/10.1108/09578239410051817

[13] Aydin, A., Sarier, Y., \& Uysal, Ş. (2011). The effect of gender on organizational commitment of teachers: A meta analytic analysis. Kuram ve Uygulamada Egitim Bilimleri, 11(2), 628-632. https://eric.ed.gov/?id=EJ927369

[14] Laugaa, D., Rascle, N., \& Bruchon-Schweitzer, M. (2008). Stress and burnout among French elementary school teachers: A transactional approach. Revue Europeenne de Psychologie Appliquee, 58(4), 241-251. https://doi.org/10.1016/j.erap.2008.09.007

[15] Buss, R. S. (2008). Administrative stress and coping preferences among female middle school principals of California in Los Angeles, Orange, and San Bernardino counties. ProQuest Dissertations and Theses. University of La Verne, Ann Arbor. Retrieved from http://turing.library.northwestern.edu/login?url=http://search.proquest.com/docview/30437589 $\underline{7 ? \text { accountid }=12861}$

[16] Wålinder, R., Gunnarsson, K., Runeson, R., \& Smedje, G. (2007). Physiological and psychological stress reactions in relation to classroom noise. Scandinavian Journal of Work, Environment and Health, 33(4), 260-266. https://doi.org/10.5271/sjweh.1141

[17] Daghestani, M. (2006). القيادة التريوية للمدرسة في ضوء مفاهيم الجودة الشاملة> Working paper presented in twelfth meeting of educational Supervision, Saudi Arabia, Medina. https://www.goodreads.com/book/show/18809471

حميد، شهد صبيح. (2019). ضغوط العمل وعلاقته بالقيادة التربوية لدى مديري المدارس. Journal Port Science ، 355-331 ، (3)2 2 Research 
[18] Ayda, N. K., Kaşot, N., \& Güneyli, A. (2018). Approaches of school administrators toward teachers with different types of human nature: The Cyprus case. Behavioral Sciences, $8(8)$. https://doi.org/10.3390/bs8080066

[19] Washington, R. R., Sutton, C. D., \& Feild, H. S. (2006). Individual differences in servant leadership: The roles of values and personality. Leadership and Organization Development Journal, 27(8), 700-716. https://doi.org/10.1108/01437730610709309

[20] Abu Tineh, A. Khasawneh, S. Tahina, Z. (2007). Servant leadership in Jordanian school as percieved by teachers and principals: exploratory study. Journal of Educational and Psychological Sciences. 8(4). http://search.shamaa.org/FullRecord?ID=79096

[21] Serrat, O., \& Serrat, O. (2017). Exercising Servant Leadership. In Knowledge Solutions (pp. 649655). Springer Singapore. https://doi.org/10.1007/978-981-10-0983-9 72

[22] Black, G. L. (2010). Correlational Analysis of Servant Leadership and School Climate. Journal of Catholic Education, 13(4). https://doi.org/10.15365/joce.1304032013

[23] Kokkinos, C. M. (2007). Job stressors, personality and burnout in primary school teachers. British Journal of Educational Psychology, 77(1), 229-243. https://doi.org/10.1348/000709905X90344

[24] Khleifat, A. أثر ضغوط العمل في الأداء الوظيفي لدى مديري المدارس الأساسية الحكومية في إقليم جنوب > . (2006) الأردن. Damascus university. https://shamra.sy/academia/show/591ad5b449f17

[25] Matsushima, H. (2008). Role of honesty in full implementation. Journal of Economic Theory, 139(1), 353-359. https://doi.org/10.1016/i.jet.2007.06.006

[26] Faraj, S. (2007). القياس النفيي> Egyptian Anglo Library. https://www.psycodz.info/2016/10/pdf $37 . h t m l$

[27] Perkins, D., \& Bishopp, D. (2017). Psychological testing. In Forensic Psychiatry: Fundamentals and Clinical Practice (pp. 559-565). Taylor and Francis. https://doi.org/10.1201/9781315380797

[28] Nias, D. K. B. (1996). The Handbook of psychological testing. Personality and Individual Differences, 20(1), 128. https://doi.org/10.1016/s0191-8869(96)90047-1

[29] Poe, M., \& Stassen, M. L. a. (2002). Teaching and Learning Online: Communication, Community and Assessment-A Handbook for Umass Faculty. University of Massachusetts, 47. Retrieved from http://scholar.google.com/scholar?hl=en\&btnG=Search\&q=intitle:Teaching+and+Learning+Onlin e+Communication+,+Community+,+and+Assessment+A+Handbook+for+UMass+Faculty\#2

[30] Oudah, A. (1985). القياس والتقويم في العملية التدريسية. Irbid: Dar Al-Amal. http://www.iraqnlaiq.com/opac/fullrecr.php?nid=126221\&hl=ara

[31] Murphy, G. L., \& Medin, D. L. (1985). The Role of Theories in Conceptual Coherence. Psychological Review, 92(3), 289-316. https://doi.org/10.1037/0033-295X.92.3.289

[32] Hollin, C. R. (2019). Personality theory. In The Routledge Companion to Criminological Theory and Concepts (pp. 46-49). Routledge. https://doi.org/10.4324/9781315744902-11

[33] Murphy, G. L., \& Medin, D. L. (1985). The Role of Theories in Conceptual Coherence. Psychological Review, 92(3), 289-316. https://doi.org/10.1037/0033-295X.92.3.289

Hammed, S. (2019). Work stress and its relation to educational leadership among school principals. Journal Pon Science Research, 2(3), 331-355. 
[34] Rosner, B., \& Cronbach, L. J. (1960). Essentials of Psychological Testing. The American Journal of Psychology, 73(2), 323. https://doi.org/10.2307/1419921

[35] Ahmed, M. (1960). القياس النفسي والتربوي> > Egyptian Renaissance Library for Printing and Publishing Cairo. https://sst5.com/BookInfysf.aspx?File no=524\&SecID=14\&CatOfE libDeptID=1

[36] Heath, R. (1964). Curriculum, Cognition, and Educational Measurement. Educational and Psychological Measurement, 24(2), 239-253. https://doi.org/10.1177/001316446402400206

[37] Hundleby, J. D., \& Nunnally, J. (1968). Psychometric Theory. American Educational Research Journal, 5(3), 431. https://doi.org/10.2307/1161962

\author{
ملحق(1) \\ وزارة التربية مديرية تربية بغداد الكرج الثالثة \\ ثانوية خوله بنت الأزور للبنات التربية \\ آراء المحكمين في صلاحية مقياس ضغوط العمل
}

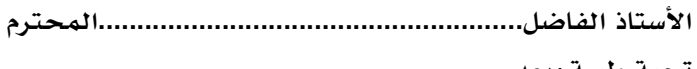

تحية طيبة وبعد

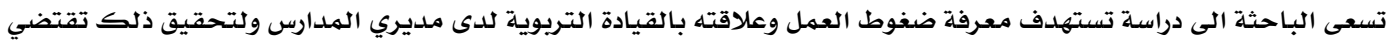

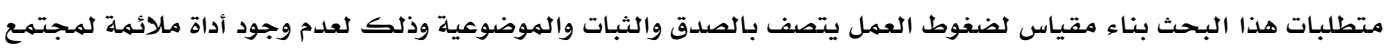

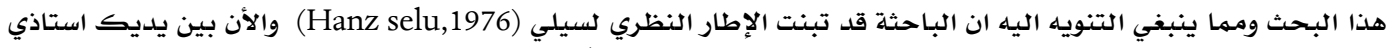

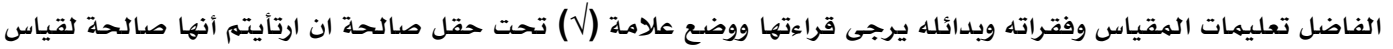

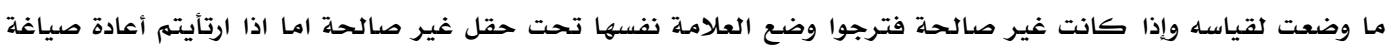

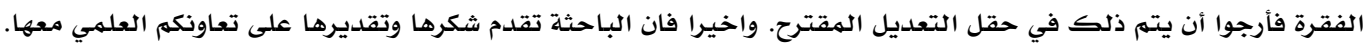

$$
\text { شهد صبيح حميد }
$$

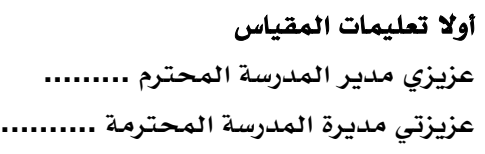

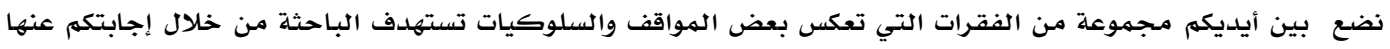

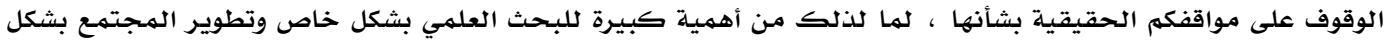

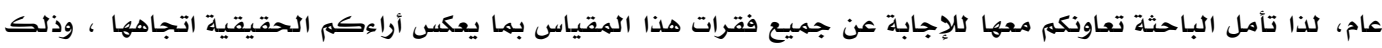

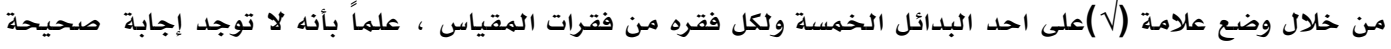

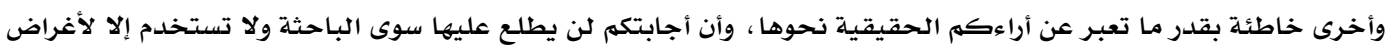

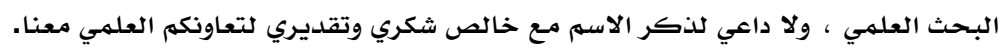

$$
\text { ثانيا بدائل المقياس }
$$

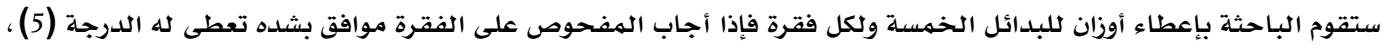

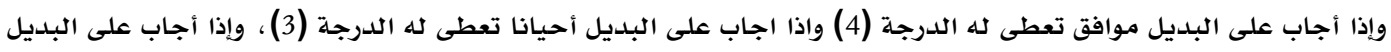

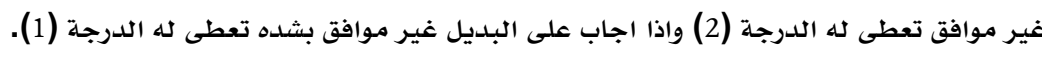

حميد، شهد صبيح. (2019). ضغوط العمل وعلاقته بالقيادة التربوية لدى مديري المدارس. Journal Port Science ، 355-331 ، (3)2 ، Research 


\begin{tabular}{|c|c|c|c|c|}
\hline التعلديل المقترح & غير صالدحة & صالحة & الفقرات & ت \\
\hline & & & اشعر بالأعياء لأقل جهد أبذله & 1 \\
\hline & & & يضايقني ما أحس بـه من نقص في دافعية طلبتي & 2 \\
\hline & & & اشعر أن الوقت المتاح لي أقل من متطلبـات عملي & 3 \\
\hline & & & اشعر بأن زيارة المشرف التربوي تهدف الى اصطيـاد أخطائي & 4 \\
\hline & & & أفقد صبري عندما لا يستجيب الطلبـة لمطالبي الدراسية منهم & 5 \\
\hline & & & أشكو من تكرار تعرضي لبعض مظاهر المرض مثل (أوجاع المعدة، & 6 \\
\hline & & & أشعر بأن اولياء أمور الطلبة لا يمنـحونني ما أستحقه من تقدير. & 7 \\
\hline & & & تضايقني مطالب المشرف التريوي & 8 \\
\hline & & & أشعر أن الكادر التدريسي يعتقدون أنني لا أؤدي عملي بشكل جيد & 9 \\
\hline & & & فرص النمو الوظيفي غير واضحة في المدرسـة & $\begin{array}{l}1 \\
0\end{array}$ \\
\hline & & & يجب أن أفعل أشياء ضد مبادئ الشخصية & $\begin{array}{l}1 \\
1\end{array}$ \\
\hline & & & عدم الشعور بأمـان للمستقبل الوظيفي بالمدرسـة & $\begin{array}{l}1 \\
2\end{array}$ \\
\hline & & & المـراجعون سريعو الانفعال & $\begin{array}{l}1 \\
3\end{array}$ \\
\hline & & & إمكانياتي وقدراتي لا تستغل بالشكل السليه & $\begin{array}{l}1 \\
4\end{array}$ \\
\hline & & & يجب ان أؤدي بعض النشاطات بطريقة أعتقد انها خاطئة & $\begin{array}{l}1 \\
5\end{array}$ \\
\hline & & & اشعر بالعجز عن التعبير لرؤسـائي عما أتعرض لله من ضغوط في العمل & $\begin{array}{l}1 \\
6\end{array}$ \\
\hline & & & أشعر بالإنهاك في نهاية اليوم المدرسي. & $\begin{array}{l}1 \\
7\end{array}$ \\
\hline & & & اشعر بصعوبة في ضبط المدرسـة & $\begin{array}{l}1 \\
8\end{array}$ \\
\hline & & & العمل في ظل سياسـات وارشـادات متعارضـة. & $\begin{array}{l}1 \\
9\end{array}$ \\
\hline & & & تضايقني تضحيتي بوقت راحتي في سبيل أنجاز متطلبـات عملي & $\begin{array}{l}2 \\
0\end{array}$ \\
\hline & & & أشعر بأني في حاجه للشكوى لغيري مها القاه في مهنة الإدارة & $\begin{array}{l}2 \\
1\end{array}$ \\
\hline & & & حجم العمل الذي أقوم به أكثر من اللازم & $\begin{array}{l}2 \\
2\end{array}$ \\
\hline
\end{tabular}

ملحق (2)

الفقرتان التي استبعدت من مقياس ضغوط العمل

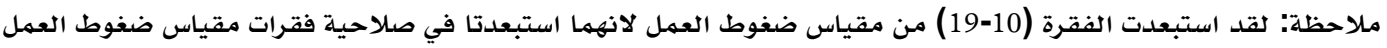

ملحق (3)

مقياس ضغوط العمل بصورته النهائية

Hammed, S. (2019). Work stress and its relation to educational leadership among school principals. Journal Pon Science Research, 2(3), 331-355. 


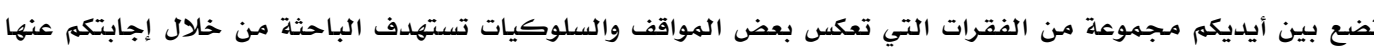
الوقوف على مواقفكم الحقيقية بشأنها ، لما لذلك من أهمية كبيرة للبحث العلمي بشكل خاص وتطوير المجتمهع بشكل عام، لدذا تأمل الباحثة تعاونكم معها للإجابة عن جميع هذه المواقف بما يعكس أراءكم الحقيقية اتجاهها ، وذلكية ولك من خلال

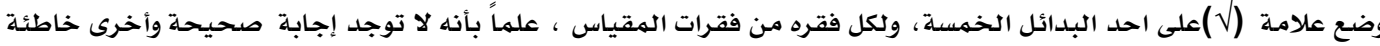
بقدر ما تعبر عن أراءكم الحقيقية نحوها، وأن أجابتكم لن يطلع عليها سوى الباحثة ولا تستخدم إلا لأغراض البحث العلمي

\begin{tabular}{|c|c|c|c|c|c|c|}
\hline \multicolumn{5}{|c|}{ 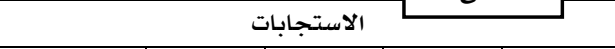 } & \multirow[b]{2}{*}{ 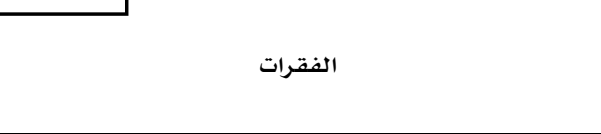 } & \multirow[b]{2}{*}{$ت$} \\
\hline غير موافق & 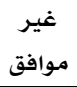 & 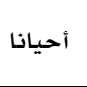 & 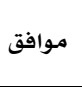 & 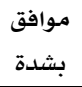 & & \\
\hline \multirow{5}{*}{ 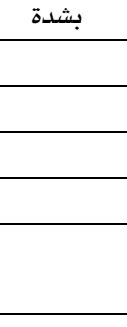 } & & & & & اشعر بالأعياء لأقل جهد أبذله & 1 \\
\hline & & & & & يضايقني ما أحس به من نقص في دافعية طلبتي & 2 \\
\hline & & & & & اشعر أن الوقت المتاح لي أقل من متطلبـات عملي & 3 \\
\hline & & & & & اشعر بأن زيارة المشرف التربوي تهدف الى اصطياد أخطائي & 4 \\
\hline & & & & & منهم أفقد صبري عندما لا يستجيب الطلبة لمطالبي الدراسية & 5 \\
\hline & & & & & أشكو من تكرار تعرضي لبعض مظاهر المرض مثل (أوجاع الام الظهر، الصداع) & 6 \\
\hline & & & & & تقدير بأن اولياء أمور الطلبة لا يمنحونني ما أستحقه من & 7 \\
\hline & & & & & تضايقني مطالب المشرف التربوي & 8 \\
\hline & & & & & جيد أشعر أن الكادر التدريسي يعتقدون أنني لا أؤدي عملي بشكل & 9 \\
\hline & & & & & يجب أن أفعل أشياء ضد مبادئ الشخصية & 10 \\
\hline & & & & & عدم الشعور بأمـان للمستقبل الوظيفي بالمـدرسـة. & 11 \\
\hline & & & & & المراجعون سريعو الانفعال & 12 \\
\hline & & & & & إمكانياتي وقدراتي لا تستغل بالشكل السليم & 13 \\
\hline & & & & & يجب ان أؤدي بعض النشاطات بطريقة أعتقد انها خاطئة. & 14 \\
\hline & & & & & ضغوط في العمل بالعز عن التعبير لرؤسائي عما أتعرض له من & 15 \\
\hline & & & & & أشعر بالإنهاك في نهاية اليوم المدرسي & 16 \\
\hline & & & & & اشعر بصعوبة في ضبط المدرسـة & 17 \\
\hline & & & & & تضايقني تضحيتي بوقت راحتي في سبيل أنجاز متطلبات & 18 \\
\hline & & & & & أشعر بأني في حاجه للشكوى لغيري مما القاه في مهنة & 19 \\
\hline & & & & & حجم العمل الذي أقوم به أكثر من اللازم & 20 \\
\hline
\end{tabular}

خامسا: مفتاح تصحيح مقياس ضغوط العمل

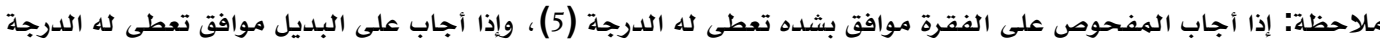

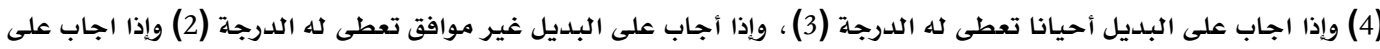

ملحق (4) من

وزارة التربية مديرية تربية بغداد الكرج الثالثة

حميد، شهد صبيح. (2019). ضغوط العمل وعلاقته بالقيادة التربوية لدى مديري المدارس. Journal Port Science ، 355-331 ، (3)2 ، Research 
آراء المحكمين في صلاحية مقياس القيادة التربوية

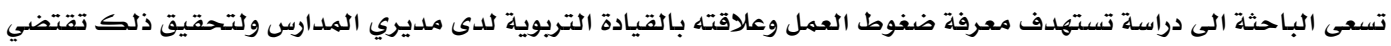

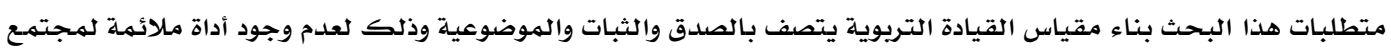

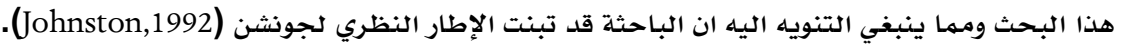

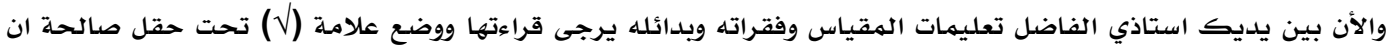

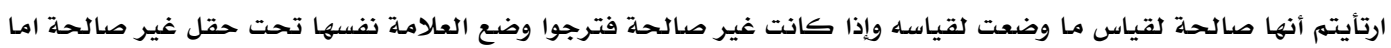

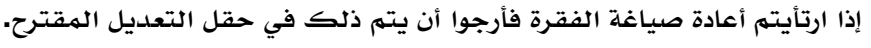
واخيرا فان الباحثة تقدم ثكرها وتقديرها على تعاونكم العلمي معها.

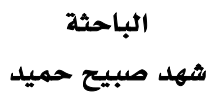

أولا تعليمات المقياس

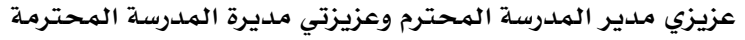

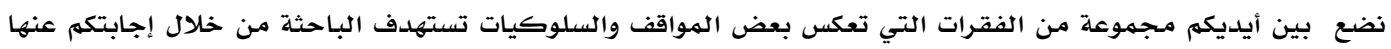

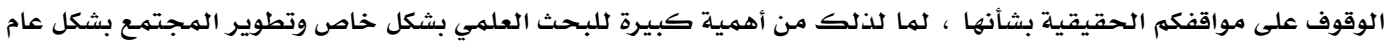

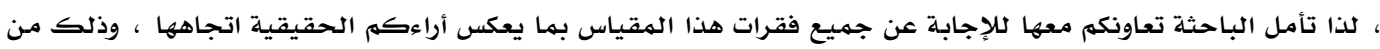

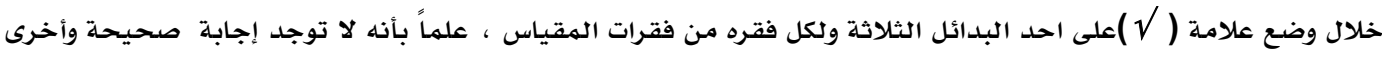

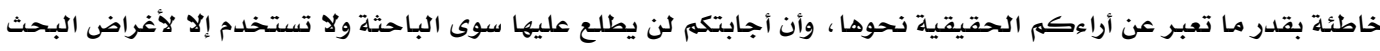

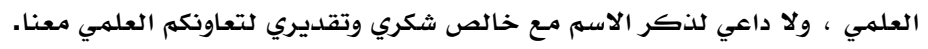

\section{ثانياً بدائل المقياس

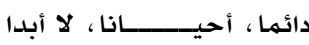 \\ ثالثاً: اوذان البداثل}

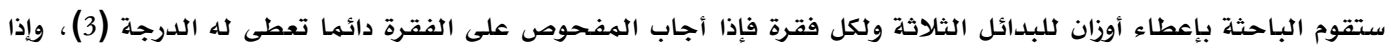

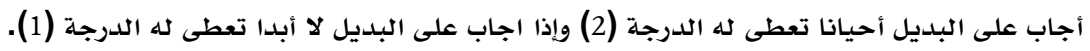

\begin{tabular}{|c|c|c|c|c|}
\hline التعديل المقترح & غير صالحة & صالحة & 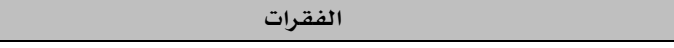 & $ت$ \\
\hline & & & أستثمر الأفكار المقترحة من المعلمين والمسؤولين & 1 \\
\hline & & & أقوم بتوزيع المسؤوليات على اللجان بما يناسب قدراتهم & 2 \\
\hline & & & أساهم في تطوير كفاءة المعلمين من خلال الدورات التدريبية & 3 \\
\hline & & & اعمل على تطوير التعليم والتعلم بالمدرسة & 4 \\
\hline & & & أقترح بدائل متعددة لحل المشكلات & 5 \\
\hline & & & أتابع السجلات المدرسية المختلفة & 6 \\
\hline & & & أتابع اعداد التقارير الفصلية والسنوية & 7 \\
\hline & & & أشجح المعلمين على استخدام الوسائط المتعددة وتقنيات التعليم & 8 \\
\hline & & & أتابع تنفيذ القرارات المتخذة وبدقه عالية & 9 \\
\hline & & & أناقش المعلمين سبل تحسين العملية التعليمية & 10 \\
\hline & & & اوجه العاملين في المدرسة نحو تحقيق الأهداف المنشودة & 11 \\
\hline
\end{tabular}

Hammed, S. (2019). Work stress and its relation to educational leadership among school principals. Journal Pon Science Research, 2(3), 331-355. 


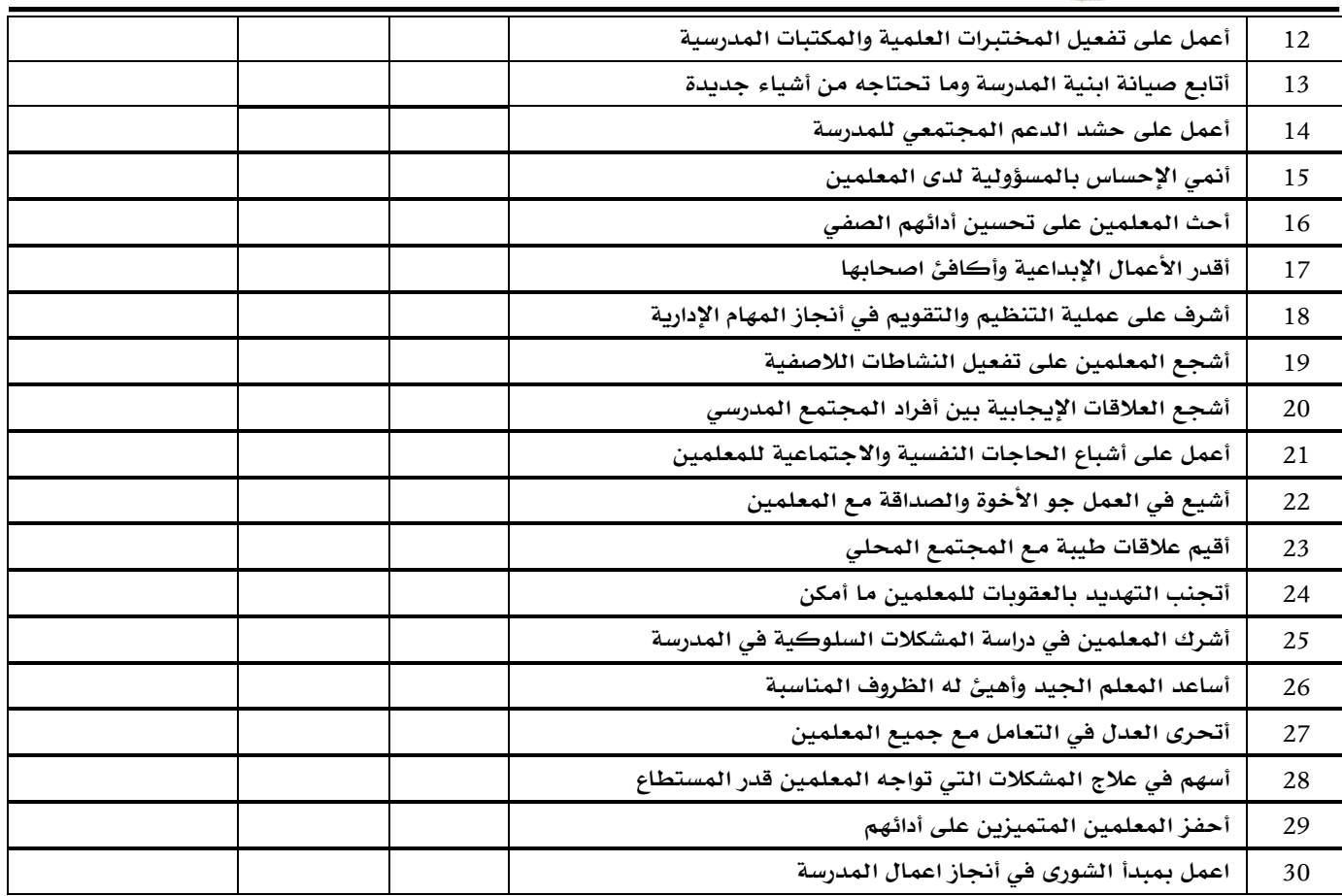

ملحق (5)

الفقرتان التي استبعدت من مقياس القيادة التريوية

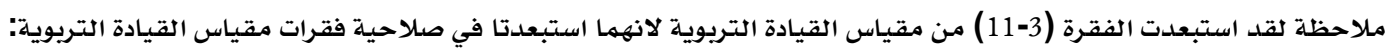

الفقرة 3 أساهم في تطوير كفاءة المعلمين من خلال الدورات التدريبية. الفقرة 11 اوجه العاملين في المدرسة نحو تحقيق الأهداف المنشودة.

ملحق (6)

مقياس القيادة التربوية بصورته النهائية

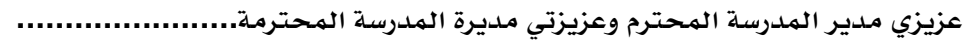
نضع بين أيديكم مجمموعة من الفقرات التي تعكس بعض المواقف والسلوكيات تستهدف الباحثة من خلال إجابتكم عنها

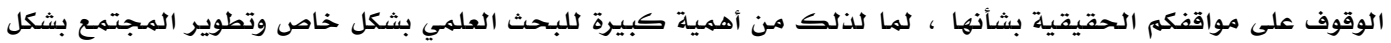

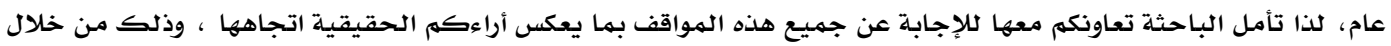

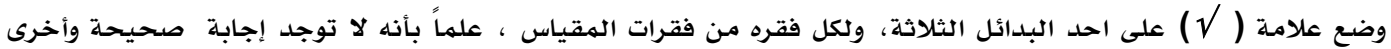

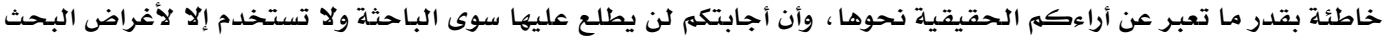
العلهي ، ولا داعي لذكر الاسهم مـ خالص شكري وتقديري لتعاونكم العلهي معنا.

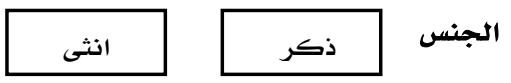

أولا معلومات عامه

\begin{tabular}{|c|c|c|c|c|}
\hline \multicolumn{3}{|c|}{ الاستجابات } & \multirow{2}{*}{ الفقرات } & \multirow{2}{*}{$ت$} \\
\hline ل الابدا & أحيانا & دائما & & \\
\hline & & & أستثمر الأفكار المقترحلة من المعلمين والمسؤولين & 1 \\
\hline & & & أقوم بتوزيـع المسؤوليات على اللجان بما يناسب قدراتهم & 2 \\
\hline & & & اعمل على تطوير التعليم والتعلمم بالمدرسـة & 3 \\
\hline & & & أقترح بدائل متعدددة لحل المشكلات & 4 \\
\hline
\end{tabular}

حميد، شهد صبيح. (2019). ضغوط العمل وعلاقته بالقيادة التربوية لدى مديري المدارس. Journal Port Science ، 

Volume:2, No:3

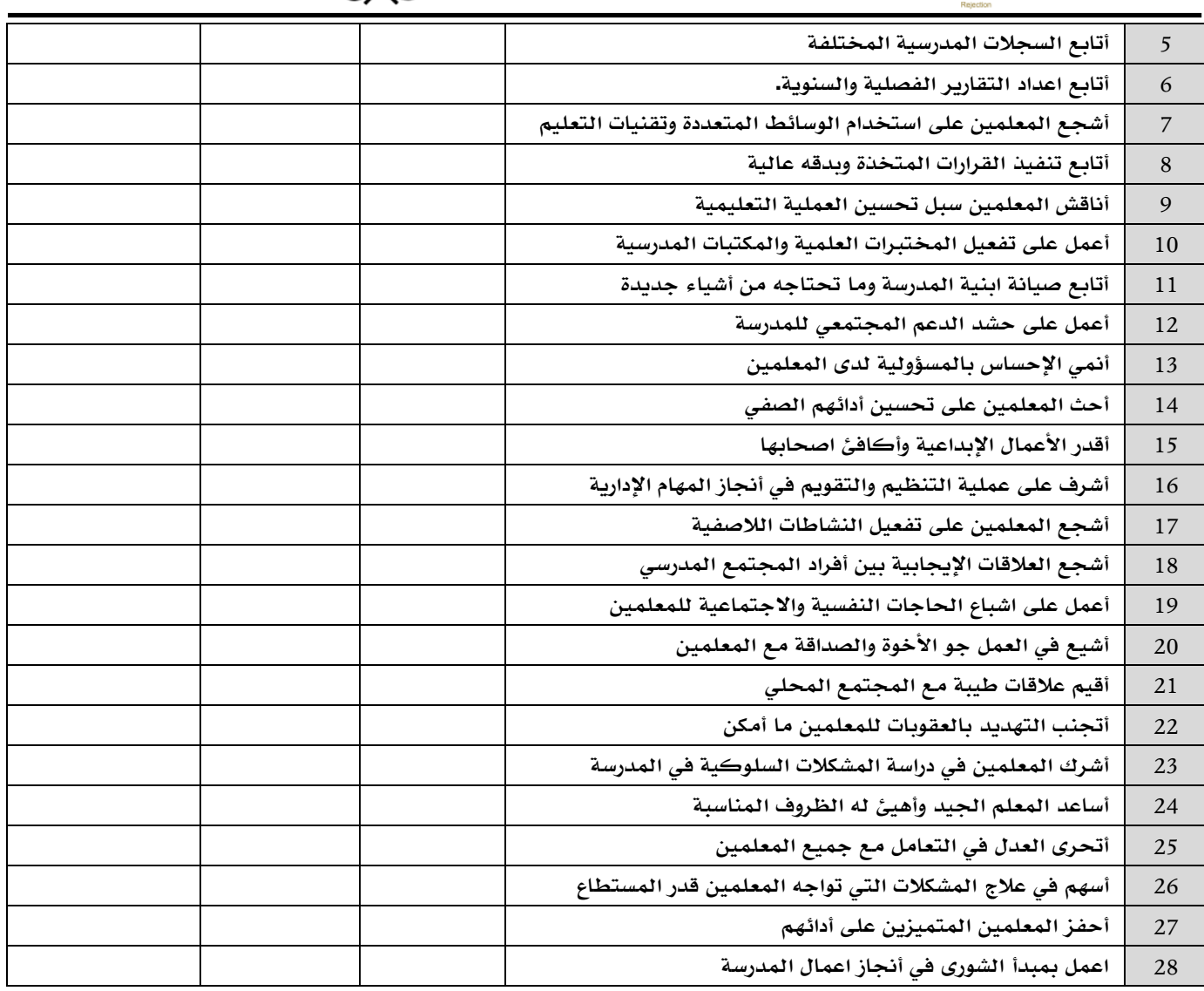

خامسا مفتاح تصحيح مقياس القيادة التربوية

ملاحظة: إذا أجاب المفحوص على الفقرة دائما تعطى له الدرجة (3)، وإذا أجاب على البديل أحيانا تعطى له الدرجئ الدية (2)

وإذا اجاب على البديل لا أبدا تعطى له الدرجة أدهابل (1).

Hammed, S. (2019). Work stress and its relation to educational leadership among school principals. Journal Pon Science Research, 2(3), 331-355. 